\title{
Considerations of the Social
} Impact of Fusion Power

by

R. D. Gastil

H. S. Markus

September 1976

Prepared for the Energy Research and Development Administration under Contract E(45-1)-1830 


\section{NOTICE}

This report was prepared as an account of work sponsored by the United States Government. Neither the United States nor the Energy Research and Development Administration, nor any of their employees, nor any of their contractors, subcontractors, or their employees, makes any warranty, express or implied, or assumes any legal liability or responsibility for the accuracy, completeness or usefulness of any information, apparatus, product or process disclosed, or represents that its use would not infringe privately owned rights.

PACIFIC NORTHWEST LABORATORY

operated by

BATTELLE

for the

ENERGY RESEARCH AND DEVELOPMENT ADMINISTRATION

Under Contract EY-76-C-06-1830

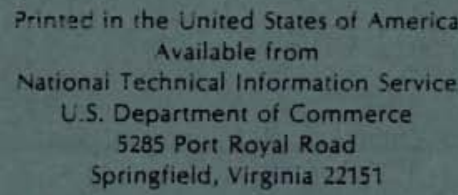

Price: Printed Copy 5 . $\therefore$ Microtiche $\$ 3.00$

$\begin{array}{lc}\text {-Pages } & \text { Selling Price } \\ 001-025 & \$ 4.50 \\ 026-050 & \$ 5.00 \\ 051-075 & 55.50 \\ 075-100 & \$ 6.00 \\ 101-125 & \$ 6.50 \\ 126-150 & \$ 7.00 \\ 151-175 & \$ 7.75 \\ 176-200 & \$ 8.50 \\ 201-225 & \$ 8.75 \\ 226-250 & 59.00 \\ 251-275 & \$ 10.00 \\ 276-200 & \$ 10.25\end{array}$


BNWL -2026

UC-20

\section{8}

CONSIDERATIONS OF THE SOCIAL IMPACT

OF FUSION POWER

by

R. D. Gastil

H. S. Markus

September 1976

BATTELLE

Seattle Research Center

Seattle, Washington 99352 


\section{PREFACE}

Fusion reactor technoiogy has developed far enough to expect laboratory demonstration of practical levels of fusion employing the D-T reaction to occur in the early 1980s. Following that demonstration, and depending upon the national priorities for energy from $D-T$ fusion, construction and operation of experimental reactors and demonstration power reactors could occur before the end of this century. Operation of the first commercial power plants could then follow, starting about 2010 .

Development and adoption of a new power system eventually will require a description of the environmental effects in an environmental statement providing a comparison to the effects of competitive systems. In anticipation of that statement, an environmental analysis (BNWL-2010) has been prepared for the ERDA Division of Magnetic Fusion Energy. That analysis estimates the environmental effects of constructing and operating D-T fusion reactors as an economically competitive source of electricity in the 21 st century.

The analysis has four primary purposes:

1. To describe the general nature of the environmental effects,

2. To determine current ability to estimate the effects,

3. To determine methods for reducing the effects, and

4. To determine research necessary for increasing capability to define and reduce the effects.

Timely identification of needed research and methods for reducing effects will permit the performance of that research and the revision of conceptual fusion power plant designs before preparation of the program environmental statement. This would improve the quality of the environmental statements and could reduce the estimated adverse environmental effects due to fusion power plants.

The environmental analysis (BNWL-2010) concludes that the following assumed characteristics are the best set for the first operating fusion power plants:

- The D-T fusion reaction

- Large quantities of activation products

- Kilogram quantities of tritium in the plant systems

- Massive reactor structures

- Large lithium inventories

- Large inventories of liquid metals and salts
- Standard electricity generation - Standard radioactive waste systems - Large magnetic fields

- A self-contained fuel cycle

- Rural siting

Using these characteristics a reference reactor was analyzed to determine the environmental effects by using available concepts of plant subsystems designs that control interactions with the environment or by assumption that best current technology would be used in subsystems design. Because this analysis does not take into account advances in both fusion and waste control technology during the next thirty years, the estimated effects probably are significantly higher than the actual effects will be for the first fusion power plants. The estimated environmental effects should be interpreted only as being the probable upper limit for the actual effects. 
Preparation of the fusion power plant environmental analysis required development and use of specially developed data and analysis methods not used in the preparation of current environmental statements for fossil and fission power plants. These data and analysis requirements are documented in a series of reference topical reports to make this information publicly available and to assure understanding of the basis for the conclusions made in the environmental analysis. These reference topical reports summarize the state-of-the-art as applicable to preparation of environmental statements for fusion power plants. They present the data and analytical techniques used in the environmental analysis to estimate the interactions with the environment and the resultant environmental effects. This information then was analyzed for adequacy and the need was determined for additional research to assure satisfactory ability to prepare environmental statements for the fusion development program and experimental facilities in the early 1980s. Estimated environmental effects are presented in these reference documents only as necessary to illustrate use of the data and analytical techniques.

This report is one of those reference documents for the environmental analysis. The other documents in this series contain more details of the power plant concepts and the probable environmental effects of fusion power plants with the assumed characteristics listed above. These documents are available through the National Technical Information Service:

An Environmental Analysis of Fusion Power to Determine Related R\&D Needs, BNWL-2010

Review of Fusion Research Program: Historical Sumary and Program Projections, BNWL-2011

Fuel Procurement for First Generation Fusion Power Plants, BNWL-2012

Current Fusion Power Plant Design Concepts, BNWL-2013

Reference Commerical Fusion Power Plants, BNWL-2014

Siting Commercial Fusion Power Plants, BNWL-2015

Materials Availability for Fusion Power Plant Construction, BNWL-2016

Projected Thermodynamic Efficiencies of Fusion Power Plants, BNWL-2017

Tritium Source Terms for Fusion Power Plants, BNWL-2018

Management of Nontritium Radioactive Wastes from Fusion Power Plants, BNWL-2019

Methodology for Estimating Radiation Doses Due to Tritium and Radiocarbon Releases, BNWL-2020

Magnetic Field Considerations in Fusion Power Plant Environs, BNWL-2021

Biological Effects of Tritium Releases from Fusion Power Plants, BNhL-2022

Biological Effects of Activation Products and Other Chemicals Released from Fusion Power Plants, BNWL-2023

Safety Review of Conceptual Fusion Power Plants, BNWL-2024

An Investigation of the Transportation Requirements of Fusion Power Plants, BNWL-2025

Considerations of the Social Impact of Fusion Power, BNWL-2026

Environmental Impacts of Nonfusion Power Systems, BNWL-2027

Environmental Cost/Benefit Analysis for Fusion Power Plants, BNWL-2028

Biomagnetic Effects: A Consideration in Fusion Reactor Development, BNWL-1973

An Analysis of Tritium Releases to the Atmosphere by a CTR, BNWL-1938 


\section{CONTENTS}

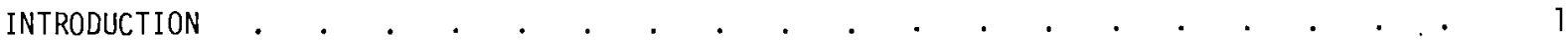

Alternative Resource Technologies . . . . . . . . . . . . . . 1

ANALYSIS . . . . . . . . . . . . . . . . . . . . . 6

Framework of Analysis . . . . . . . . . . . . . . . . . . . . 6

The Framework as Model. . . . . . . . . . . . . . . . 10

Recent Energy History. . . . . . . . . . . . . . . . 12

The Social Impact of Fusion: General Considerations . . . . . . . . 14

Specific Arguments . . . . . . . . . . . . . . . . . . . 18

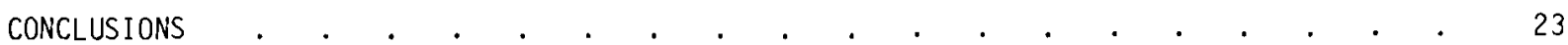

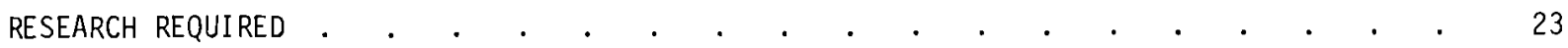

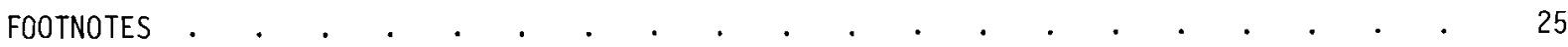

APPENDIX I : ENERGY RESOURCE/TECHNOLOGY ANALYSIS . . . . . . . . . . . . . 31

APPENDIX II: MICROANALYSIS . . . . . . . . . . . . . . . . . . . . . 35

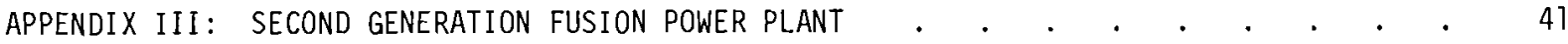

APPENDIX IV: SELECTED TECHNICAL ENERGY BIBLIOGRAPHY . . . . . . . . . . . . . 45

Articles/Papers . . . . . . . . . . . . . . . . . . . . . . 45

Books/Reports . . . . . . . . . . . . . . . . . . . . . . 47

\section{LIST OF ILLUSTRATIONS}

Figure

1 The General Framework for a Social Decision . . . . . . . . . 7

2 Framework for an Energy Decision . . . . . . . . . . . . . . 9

II a PSPL Corporate Planning and Management System . . . . . . . . . 37

IIb Internal Flows and Interconnections Between CPMS/PSPL/PA/ME. . . . . . 38

IIIa U.S. Energy Use Forecasts . . . . . . . . . . . . . . . . 44

\section{LIST OF TABLES}

Table

1 Idealized Dominant Resource/Technology Alternatives: 1975-2025 A.D. . . . 2

Ia Energy Resources . . . . . . . . . . . . . . . . 32

Ib Energy Resource Analysis Criteria--Macroanalysis . . . . . . . . 33

Ic Projected Analysis of Energy Resources A.D. 1975-2025 . . . . . . . 34

IIIa Possible Uses of Thermal Energy (Waste Heat) . . . . . . . . . . . . 42

IIIb Comparison of Two 2010 A. D. Forecasts . . . . . . . . . . . . 43 


\section{ALTERNATIVE RESOLIRCE TECHNOLOGIES}

For the purpose of evaluating the social impact of fusion power systems, we propose four ideal types of energy resource/technology. These are considered in the framework of an interactive systems diagram that allow relevant social science theory and data to influence the analysis of the directions and magnitude of influence and feedback among relevant factors. There is an explicit, if sketchy, attempt to make the assumptions of the study open to both theoretical and empirical criticism. Since both the social situation and the non-social characteristics of the alternative future technologies impacting upon the situation in the post-2000 period are both largely unknown, the analysis is in large part an exposition of if then cases. Therefore we are concerned with the exposition of a methodology that might become increasingly useful as the technological facts and the non-technological situation after the turn of the century are approached in time. With these caveats, we conclude that the direct effects of fusion technologies of the same ideal types, are socially more desirable than those of alternatives. This is particularly true of the second generation fusion power plant.

The task of assessing the social impact of the fusion power system in the early twenty-first century is quite different from less global or more immediate assessments. Since we cannot know what the state of energy technology, capital requirements, or energy consumption level will be twenty-five years ahead, we can be easily misled as to the advantages and disadvantages of future alternative energy technologies. The purpose of an environmental study this far ahead of development and widespread use must be to improve the understanding of the Energy Research and Development Administration (ERDA) and the public for the relative advantages of all energy systems that have roughly equal chances of filling the short-fall in projected energy production at competitive economic cost beyond the year 2000. Only against this spectrum of possibilities can we adequately assess the comparative social impact of the fusion power system.

Therefore, for the social assessment, six alternative energy resource/technologies were considered (Table 1). These alternatives were constructed on the basis of the assumptions of energy resources in the tables in Appendix I. Each alternative represents a dominant resource/technology combination (i.e. the resource/technology that is producing the largest portion of a given period's power requirements or in which most investment is being made). Technologies 4-6 (solar and fusion) and to some extent 3 (fission) will be treated as dominant only in the latter sense. These alternatives will be considered in terms of macro- rather than micro-analysis, although the latter (site analysis) is examined briefly in Appendix II. As, and if, the several technologies develop further, additional and more specific research on comparative social impacts should be undertaken, the results of which may then feed back into the setting of non-social R\&D policy. 
In the Base Case (Table 1) the dominant technology is conventional fossil fueled thermal electric supplemented by hydroelectric and non-breeder reactors. Over the 1975-2000 period, a progressive shift toward nuclear power is expected. Alternative 2 (Total Energy) is based on the same resources as the Base Case but represents a major national effort to preserve and extend the use of these resources through energy conservation, that is, to place primary emphasis on improving the efficiency of the use of our energy and capital resources. Some energy analysts feel that an effective national energy conservation program offers the best path of transition to a future solar, breeder or fusion based energy system. The Total Energy Case includes a mix of non-breeder reactors, coal in a variety of end forms, increased recovery of petroleum, solar for special uses, geothermal, and conversion of municipal refuse and sewage, with special attention given to energy conservation. Normally, about $65 \%$ of fuel energy is unusable in the generation of electricity and this "waste" heat is rejected to the environment as thermal pollution. One way of utilizing this energy more efficiently would be the Modular Integrated Utility System (MIUS) concept being pursued by the U.S. Department of Housing and Urban Development. In the development of MIUS the five necessary utility services for a community i.e., electricity, space heating and cooling, solid and liquid waste processing, and domestic water supply are provided in one decentralized processing plant. The system would conserve natural resources, reduce total energy demand by increasing utilization efficiency, and minimize environmental impact. 1

TABLE 1 Idealized Dominant Resource/Technology Alternatives: 1975-2025 A.D.

\begin{tabular}{|c|c|c|c|}
\hline $\begin{array}{l}\text { IDEAL } \\
\text { TYPE }\end{array}$ & $\begin{array}{l}\text { DOMINANT } \\
\text { TECHNOLOGY }\end{array}$ & $\begin{array}{l}\text { DOMINANT } \\
\text { RESOURCE }\end{array}$ & GENERAL CHARACTERISTICS $1 /$ \\
\hline \multirow{2}{*}{ A } & $\begin{array}{l}\text { 1. BASE CASE } \\
\text { (Current } \\
\text { Technology) }\end{array}$ & $\begin{array}{l}\text { FOSSIL } \\
\text { RENEWABLE } 2 / \\
\text { URAN IUM }\end{array}$ & $\begin{array}{l}\text { Existing } 1975 \text { system, supplies for one or two centuries, } \\
\text { generally large plants, rural siting, greater hazard/ } \\
\text { pollution/despoliation... }\end{array}$ \\
\hline & $\begin{array}{l}\text { 2. TOTAL } \\
\text { ENERGY }\end{array}$ & $\begin{array}{l}\text { FOSSIL } \\
\text { RENEWABLE } 2 / \\
\text { URANIUM }\end{array}$ & $\begin{array}{l}\text { 1975-2010 application, strong conservation program, decentral- } \\
\text { ized solar, siting of generation plants in load centers, low } \\
\text { to moderate hazard/pollution/despoliation... }\end{array}$ \\
\hline$B$ & 3. FISSION & $\begin{array}{l}\text { URAN IUM } \\
\text { PLUTONIUM }\end{array}$ & $\begin{array}{l}1990^{\prime} \text {, breeder reactor based, very long-term (thousands of } \\
\text { years) major research \& development program underway, rural } \\
\text { siting, low despoliation, moderate pollution, greater hazard... }\end{array}$ \\
\hline C & 4. FUSION-I & $\begin{array}{l}\text { DEUTERIUM } \\
\text { LITHIUM }\end{array}$ & $\begin{array}{l}\text { A.D. } 2010 \text {, yet to be demonstrated, long-term, increasing } \\
\text { research and development program, rural siting, moderate } \\
\text { hazard, low pollution and despoliation... }\end{array}$ \\
\hline \multirow[t]{2}{*}{$D$} & $\begin{array}{l}\text { 5. } \\
\text { SOLAR- } \\
\text { MIXED }\end{array}$ & RENEWABLE $\underline{2} /$ & $\begin{array}{l}21 \text { st Century, assumes major breakthroughs, very long-term } \\
\text { urban and rural siting, centralized and/or decentralized, } \\
\text { lower pollution/despoliation/hazard... }\end{array}$ \\
\hline & 6. FUSION-II & $\begin{array}{l}\text { ADVANCED } \\
\text { FUELS }\end{array}$ & $\begin{array}{l}21 \text { st Century, very long-term, assumes major breakthroughs, } \\
\text { urban and rural siting, probably centralized, lowest hazard/ } \\
\text { pollution/despoliation... }\end{array}$ \\
\hline
\end{tabular}

iNOTES: $\quad$ This table is based on the analysis of energy resources in Appendix 1 . The general characteristics show the relationship between the technologies listed here and are not related to present technologies.

1) Assuming reasonable cost and effective measures to mitigate hazards and/or environmental impacts.

2) Renewable resources include solar -- physical/biological/direct, geothermal, municipal refuse and sewage, gravity .. hydro and tidal, and other exotic sources. 
Alternative 3 (Fission) assumes that most power is produced by fission reactors, which probably means growing dependence on LMFBR or another breeder reactor technology. The breeder reactor would extend the low cost uranium resource for centuries, reduce environmental impacts as compared with the Base Case, and provide substantial economic benefits in terms of low-cost energy. It would also increase the amount of plutonium used by industry by several orders of magnitude. This would make necessary complex controls for this highly toxic substance, requiring the safeguarding of nuclear materials and facilities against theft or sabotage and the development of a more adequate technology for the permanent disposal of radioactive wastes. ${ }^{2}$ . Some persons ${ }^{55}$ associated with present-day fission technology believe that the availability of uranium and fossil fuels at not unreasonable prices together with the problems associated with the LMFBR and fusion programs will preserve the dominance of alternatives 1 and 2 beyond the turn of the century. Others, however, see the LMFBR in alternative 3 (Fission) becoming dominant sometime after 1990, and certainly before 2020 in the absence of successful fusion development. Its primary advantage will be lower fuel costs as available uranium becomes scarcer. We can assume that this advantage more than offsets possibly higher installation or hazard reduction costs, for if it does not the technology is unlikely to become dominant. ${ }^{3}$ Breeders will probably have higher hazards than non-breeders, but will not despoil the environment to the same extent. Nevertheless, for the purpose of comparison with fusion power systems, fission technologies are of sufficient similarity to be considered together, especially if the continued use of non-breeders beyond the turn of the century is dependent on the development of breeder reactor technology.

0ther technologists 56 and influentials believe that emphasis on any fission technology will result in unnecessary environmental costs. Some see fusion as the eventual answer, but they believe that before the fusion power system is developed a combination of other technological and conservation efforts will adequately fill the gap. In Table 1, we have tried to frame this interest with two alternatives. The first, alternative 2 (Total Energy) based essentially on known technology, would be a desirable alternative to apply as a dominant technology until about 2020, assuming a low rate of growth in energy consumption. Alternative 5 (Solar-Mixed) offers a non-nuclear alternative which might be fully competitive with all other sources if there were major technical breakthroughs, especially in lowering the costs of the direct conversion and storage of solar energy. 4

It is against this background that we must consider the two fusion alternatives. Alternative 4 (Fusion-I) is a first generation system using deuterium-tritium as fuel, perhaps supplemented by fusion-fission hybrid systems. Such power plants are assumed not to be located in urban areas, material requirements for plant fabrication may be high compared to the known resource base, and hazards may not be negligible (see below). Alternative 6 (Fusion-II) is a second generation system that solves most of these problems. In particular, by reducing hazards an advanced system could be sited in cities and thus reduce transmission and distribution costs. In addition to providing low-cost, virtually limitless energy, the waste heat from such a plant could be used for district heating and industrial process steam (see Appendix III). 
It is significant that in the LMFBR environmental study the role of the fusion power system, presumably alternative 4 , in power generation in A.D. 2020 was estimated as no more than that of solar energy at that date. ${ }^{5}$ This conclusion seems reasonable as the scientific and engineering breakthroughs necessary to achieve competitive solar power (alternative 5) seem no more difficult than those for fusion. We do not know the date either will arrive, but present information suggests that alternatives 4 and 5 should be placed in approximately the same future period. However, to avoid getting into a profitless fusion versus solar controversy at this time we have decided to conclude that we have been asked to study the possible social impacts of "idesal types" 6 of dominant technologies as summarized in Table 1 . We will be considering the impacts of systems with the characteristics of ideal types C (alternative 4) and D (alternatives 5 and 6 ), versus those of ideal type $A$ (alternatives $1 \& 2$ ), on the one hand, and ideal type B (alternative 3 ) on the other. What technologies actually achieve these objectives must be left to the future. The remainder of this discussion refers to those energy systems with the characteristics of alternatives 4 (fusion I), 5 (solar-mixed) or 6 (fusion II) in whatever way they may be attained technically.

While the cost of energy produced by first generation fusion power plants is hard to estimate, efforts to make an advanced fission system of equivalent safety and therefore acceptability may give fusion a cost advantage. On the basis of present information we have no reason to believe we will be faced with the really difficult question of the tradeoffs between a low-cost but dangerous fission system and an expensive but safe fusion system. The "low hazard" of the fusion power system should be given several qualifications. It may be, for example, that tritium will be more difficult to contain than has been hoped, and its leakage to the natural environment may have significant consequences if power is produced in large and increasing quantities using deuterium-tritium fuel. Fusion power plants may require frequent maintenance, and the operation and decommissioning of these facilities may be more difficult than is now expected. Finally, there could occur a concern for diversion in a way analogous to plutonium from breeder reactors for the construction of explosive nuclear devices. This will become increasingly probable with the continued development of laser technology which might make the fission trigger of a hydrogen bomb unnecessary. It is assumed that the fusion system would have a low despoliation rate due to the negligible mining requirement to produce fuel and the limited area needed for facilities. Of course, raw material requirements for the construction and periodic replacement will require disturbance of land to obtain required materials, although the areas involved may not be extensive.

Turning to ideal type $D$, second generation fusion power plants (alternative 6) could have no radionuclides in the system, heat release rates lower than those for the best current coal plants, and would allow urban siting. Although these facilities would be linked via powergrids to allow for maintenance, we assume reduced needs for transmission facilities with both economic returns and improved aesthetics. In this alternate the development of advanced fuel fusion power results in a major reduction in the cost of electricity. In alternative 5 (Solar-Mixed) there will be more central station generation and transmission facilities and thus greater 
despoliation than in the second generation fusion system. Yet with continued population movement toward the southern portion of the country, well developed onsite energy storage, and intensive development of the other parts of the mixed system, onsite solar generation could provide a major portion of national energy requirements in the year 2020 . 


\section{ANALYSIS}

\section{FRAMEWORK OF ANALYSIS}

Technology assessment has been described in terms of a variety of checklists of observed or potential impacts. In terms of social assessment these include three general fields: the area of impact, the groups impacted, and the level of impact. The impacts of fusion technology may be compared in terms of impacts in areas such as national security, economic growth, opportunity, health, education, safety, transportation, recreation, or aesthetics. Each of these impacts may be analyzed by population subgroups, analyzed by age, sex, region, socioeconomic class, or dominant interests; and the impacts considered may be primary, secondary, or higher order. In each case we would want, of course, to look at the probability, magnitude, and controlability of the impact, and then to reanalyze projected impacts with alternative mitigating measures. 8

The foregoing is essentially the approach taken by the AEC and ERDA in the analysis of the environmental impact of the LMFBR, with notes on some of the different impacts that fusion would have in comparison. ${ }^{9}$ Many of the facets of technology assessment were not addressed in this analysis, either because they were of slight importance to the technologies assessed, or because they would be best analyzed in terms of microanalysis (site selection) rather than macroanalysis (the overall evaluation of the technology).

Our interest is macroanalysis, and since so many of the characteristics of fusion and other future energy systems are still poorly specified, it would be preferable to take this opportunity to sketch a more theoretical and less ad hoc approach to social assessment. In the course of this we can incorporate many of the checklist items in a way that may be more suggestive of the consequences of these energy technologies as they develop. This seems particularly necessary because of the importance attached in the literature to getting beyond direct consequences to higher order impacts. To do this an approach must be developed that is more open to useful theoretical argument than has generally been the case in other studies that specify social changes as the indirect result of particular technological innovations.

In order to achieve these goals we have adopted an analytic framework for relating dynamically to one another the major factors that social scientists have seen as explanatory of behavior. 10 In a highly abstract form (Figure 1) the framework presents in an interactive diagram:

- those biosocial "laws" (pressures and limits) of group behavior that have been developed by generalizing social sciences such as sociology, economics, or political science;

- the biological description of the parameters of individual human behavior developed by biology and psychology;

- the society specific generalizations (or cultures) that have been described by anthropology; and

- the situational attention to prior idosyncratic detail of the historian, lawyer, or journalist.

Each of these interact upon any chain of events leading to the particular situation with which we are concerned. 


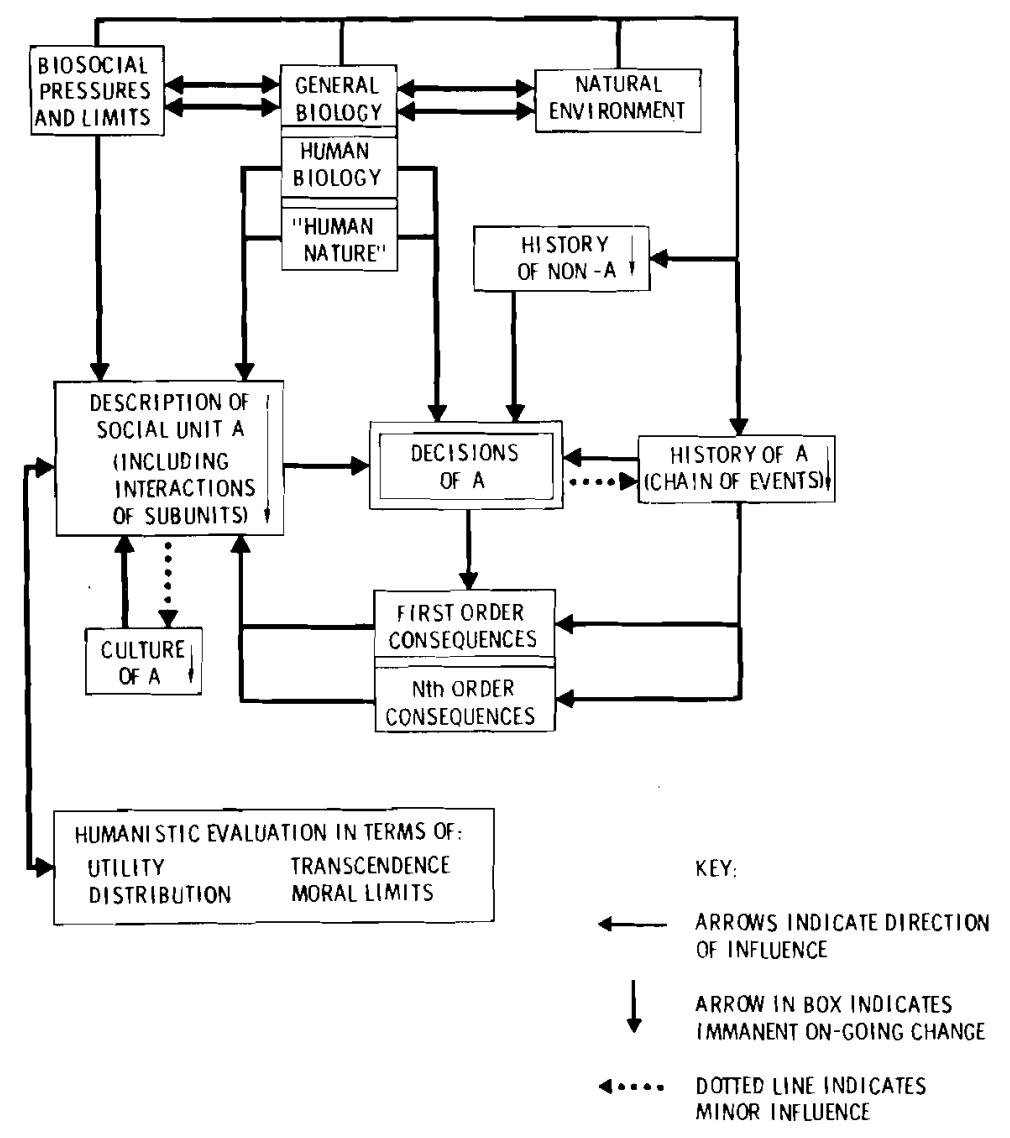

FIGURE 1 The General Framework for a Social Decision

A thorough scientific understanding of the ramifications of a decision could theoretically be obtained through working out the specifics of Figure 1. But, of course, this would not make possible an evaluation of whether the decision should or should not have been made. To do this at some point in the analysis an evaluation in terms of values and goals must be included. Most analyses treat value and goals as cultural, and so try to incorporate them in social science, but in Figure 1 we have separated an understanding of what American values are from what an analyst on reflection believes they should be. While many consumers of research and analysis claim to be uninterested in the personal opinions of the analysts, this is a mistake for at least two reasons. First, most analysis in the social sciences reflects personal values, and where science ends and personal values begin is too often unclear to the reader. Explicitly separating personal evaluation from scientific judgment should encourage the responsibility of the latter, for it allows the analyst to express his value conclusions as a separable part of his advisory role. " Secondly, there exists a considerable literature in philosophy and the softer humanities that has a contribution to make to serious ethical, moral, and aesthetic judgment. By labeling a separate area of personal evaluation as humanistic judgment we encourage both the analyst and the reader to move to a more reflective level of concern than is usually implied by the expression "personal opinion." 
The decision areas suggested for non-scientific evaluation are those of utility, distribution, transcendence, and moral limits, with the assumption that the investigator will work out at least some vague decision rules for the weighing of each concern against the others. 12 In the following analysis we will consider the balance between overall social utility (the general measure of most technologies), the distribution of utility (see the discussion of no-growth alternatives below). The extent to which moral limits should be placed on certain kinds of actions even though there are not convincing utility arguments against them is also discussed. For example, while individual murders may be socially desirable, most societies have decided to establish an absolute rule against murder. Transcendence, or going beyond the normal human limits, should also be an important concern of policy, even though we will not develop its implications here. More generally, analyzing the balance of these four types of humanistic considerations is a much neglected area in the analysis of policy questions, such as surround the development of the fusion power plant.

For the purpose of studying the social impact the next step is to translate the generalities of Figure 1 into Figure 2. Here we have specified a number of situational characteristics of the energy question both as it exists within the American social system and external to it. Biological man is subsumed for this purpose in the biosocial influence upon the problem, and all diagramed relationships are expressed under the influence of biosocial pressures and limits. Some relationships also express the rather "harder" physical constraints 0 . the real world (e.g. the depletion of a resource). In evaluating Figure 2 remember that the critical issue to determine is often the qualitative or quantitative influence of one factor upon another, and the determination of these dimensions may be very difficult. Also note the importance of time lags between change in one variable and its reflection in other variables, delays that are particularly characteristic in cultural changes.

In the framework we consider American society as having inputs from four sources: 1) the traits of American culture, 2) the physical environment of the country, 3) national consumption patterns, and 4) the relevant decisions and conditions in the rest of the world. This American society has as outputs energy decisions and the cost and supply of energy, with their several further interactions.

What goes on in American society is the primary determinant of the decisions that emanate from $i t$, as well as of the ways in which inputs to the society are received and evaluated. The evaluation of energy issues depends significantly on the place that energy issues occupy in the society at any given time. For the energy issue we identify four groups of decision makers: the public is the most general group, comprising individuals without any specific occupational interest in a decision, but also individuals who will be affected generally by it (but see below); the "energy industry" includes all of those with responsibility for providing energy (with ERDA between the industry and political leadership); the political leaders are those directly or indirectly making decisions ostensibly on behalf of the public (formally, they serve as staff to the public or as representatives of the public, while the industry transacts 


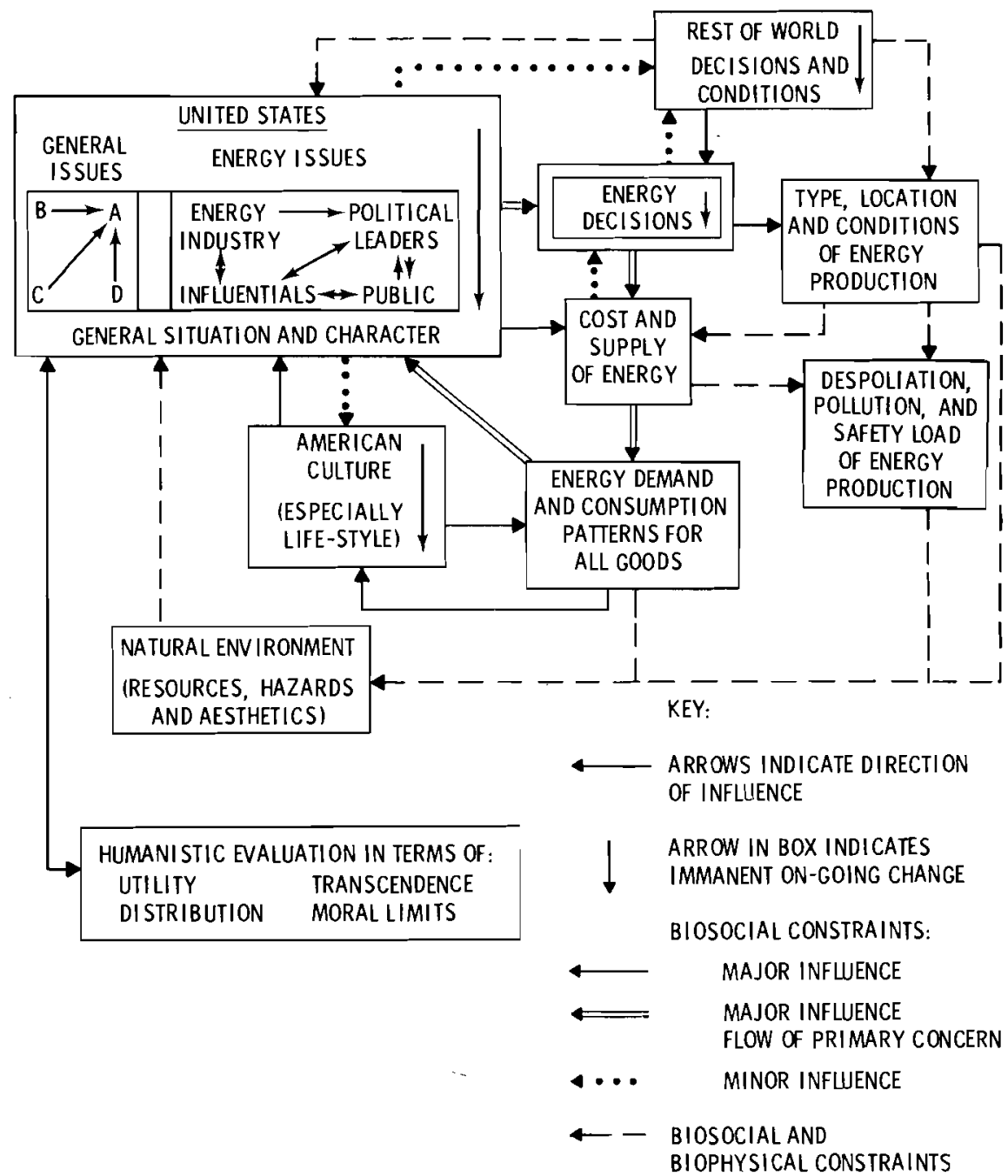

FIGURE 2 Framework for an Energy Decision

with the public and its political leaders to provide energy); the influentials, finally, are those persons who do not have a direct interest in energy, other than as communicators. The role of influentials is to aid in opinion formation (as ministers, teachers, editors, advisors, consultants, etc.)--ideally they inform and lead others in their society through professional attention to pure knowledge, rationality, humanistic evaluation, and consideration of the longterm future. Their practical interest (either because of income or status desires) is to maintain credibility with the public and those special elites they attempt to influence.

In this model the public's wishes are nominally defined in terms of the wishes of the majority of people as expressed directly or through their representatives at any one time. However, "the public" may also be understood to stand for those ideological interest groups relevant to an energy decision. 13 These may involve or be led by influentials, although they may also be organized by energy industrial or political leaders. In a pure interest aroup approach the political leaders would be seen as brokers among a yariety of issue-specific groups including influentials and energy industry. Unless the public accepts an issue as of critical general interest, ideological interest groups may bring pressures as though they represented the 
majority. This is as though our system allowed weighted voting in terms of the intensity of the interests of the individuals participating. 14 The result in policy is a compromise among the interests of those most concerned, a result somewhat different from, but not repugnant to, our political system (see Appendices).

\section{THE FRAMEWORK AS MODEL}

The framework for decision is a minimum qualitative model in that it implicitly makes the claim that the factors and relationships represented are the most important for considering the overall social impacts of a new energy technology. However, the model becomes more powerful if we can add scientific laws, hypotheses, or hunches in terms of which changes in one factor are seen to have an influence of known direction on another within the framework. To do this we will need to specify the biosocial principles, or constraints, that will operate within the model (leaving the biophysical constraints primarily to others). These constraints then need to also be interpreted in terms of how they operate on Americans and American society (i.e. in terms of the culture, and its expected evolution).

Although social science represents a wide variety of different fields and theoretical approaches, some of which could lead to different conclusions within the framework, analysis can proceed coherently if we adopt that strand of simplified social science that has been developed in market economics and learning theory as a "first approximation" for analysis. 15 As the analysis proceeds the rest of social science can then be brought in to modify this approach when appropriate.

In examining the relative social advantages or disadvantages of the fusion power system, we will then be guided by the following biosocial (B), cultural (C), and situational (S) assumptions:

1) Energy consumption wizl vary with the price of energy, ard price wil: way with availabizity. (B)

Comment: Basic economics. 16 Demand not immediately elastic, but over time the assumption will be confirmed, especially when "price" reflects costs to whole economy. of course, the government can and does interfere with the market to encourage, discourage, or refocus energy production and consumption.

2) Within limits, the public will prefer inexpensive, generally available energy cuer more expensive, less available energy. (B)

Comment: Basic economics for any good. Low availability can be considered an added cost paid by the consumer. Because of projections under assumption \#7, unless the year 2000 energy system is markedly more dangerous or polluting than that in 1980, cost and avai1ability will have priority over other considerations.

3) Within limits the public will prefer systems with zower non-economic costs. That is, it will prefer systems perceived to be safer, less polzuting, and less despoiling over systems perceived to be more so. (B)

Comment: Common sense. Place of fear or health in emotional hierarchy indicates they will be taken quite seriously. ${ }^{17}$ Concern for safety, health, and aesthetics is always important, but relative importance and quality varies widely among individuals. 18 
3a) The Public will perceive risks to life resulting from the provision of public goods not individualzy chosen as possibly unacceptable if they are greater than those of natural disasters (1 in a mizizon years) and certainly if greater than the threat of fatal disease (1 in 100 years). (B,C)

Comment: Based on studies of apparent public acceptance of a variety of risks. ${ }^{19}$ For voluntary and private activities people sometimes accept (or even prefer) much higher dangers, but not for public goods. ${ }^{20}$ (But see assumption 6c.)

4) Since the public wizl prefer systems with zow economic and non-economic costs, it wizl reward with continued support industry and government to the degree that it perceives that they have done a good job in providing these systems. $(B, C)$

Comment: Follows from the definition of the economic and political system. 21 Perceptions are hard to forecast, since expectations may be so high that the best policy would be perceived as a failure. ( $B, S, C)$ Public may not understand the reality constraints of the present and projected state of the internal physical environment and the external state of the world. (S) However, assumptions 6, 6a, and 7 will damp this danger.

5) Within limits, the public wizl be wizling to exchange higher economic costs for lower noneconomic costs of projected energy systems. (B)

Comment: Follows from assumption 3 above. But a wide variation of projected exchange rates possible. On possible changes in rates see specific argument $\underline{3}$ ( $p$. 21 below).

6) The public wizl come to perceive the safety and pollution levels of systems in rough accord with state of technical knowledge of these levels. (B)

Comment: Diffusion of knowledge. ${ }^{22}$ Empirical studies of popular information. ${ }^{23}$

6a) The public will accept the evidence of the majority of influentials, but the public's final judgment may differ from that of the influentials, because of different values. (B)

Comment: Diffusion theory. ${ }^{24}$ The public is more inclined to accept factual information than opinion because of its non-elite initial values and continuing value stability. ${ }^{25}$

6b) The public wizl accept new facts with a time $\mathrm{lag}$. (B)

Comment: This reflects the S-shaped curve of innovation acceptance. ${ }^{24}$ (B) Lag may produce critical problems as suggested in the comment to assumption \#4 above.

6c) Perceptions of some dangers may be so generalized as to limit development of technically unrezated systems. (B)

Comment: Problem of lag in conceptual differentiation, especially when related to fear and anxiety. 26

6d) The public wizl be able to force decision makers to accept their judgements in areas of "critical general interest." (C,B)

Comment: Theory of the democratic form of government. Affected by long-term selfinterest of decision makers. 27 Using Anthony Downs' terms, an issue becomes of "critical general interest" when it has passed the stage of alarmed or euphoric discovery and entered that of realization of the costs of pursuing the full implications of the discovery. $^{28}$ Low interest is frequently evidenced by "don't know" or "no opinion" responses to issue-related questions in polls. 
6e) Influentials, energy costs, and discontinuities in supply will periodically make energy an area of critical general interest. ( $B$ )

Comment: Since the projection of the current situation shows projected energy needs and resources not in equilibrium, there will be recurrent public dissatisfaction. ${ }^{29}$ (S) This will be exacerbated by the professional need of influentials to identify developing problems. 30

7) Influentials will communicate state of art energy information about energy alternatives with minimum distortion by no-growth ideology. (B)

Comment: Most people are highly materialistic, especially as reflected in desired consumption, ${ }^{31}$ and influentials must reflect this materialist interest to a large degree or lose influence. 32

\section{RECENT ENERGY HISTORY}

In a dynamic world the characteristics of each factor is continually changing because of successive inputs from others, inputs that it in turn processes and passes on, while some factors change for reasons that are inexplicable in terms of the modeled system (e.g. because of fashion, or the internal problems of other nations that are not directly taken into account in Figure 2).

The operation of the system described in Figure 2 was characterized from 1800 to 1970 almost entirely by growth, or positive feedback. ${ }^{33}$ Growing consumer demand for goods directly and indirectly increased demand for energy. This led to technological and organizational change that expanded supply of energy and economic growth, and these in turn further extended demand, as they allowed consumer demand to expand. Whatever losses occurred were absorbed by the environment. And as the process developed, the increases in demand and in technology were sufficiently regular that projections of future demand were made the basis of large capital investments. These investments then required that demand be encouraged to justify them, so that projected demand rather than active demand increasingly came to drive the system. Gradually more and more of the world contributed to positive feedback, and poor countries with energy supplies began to become wealthy, and use of these low-cost supplies helped both poor and weal thy countries to grow economically.

It is important to realize that there have always been losses. It has long been known that resources were being used up, but this has not been an inhibiting factor for three reasons. First, the expansion of fossil fuel reserves kept ahead of their exhaustion at least until the late sixties, and persistently showed previous warnings of iminent depletion to have been in error. New fossil resources in the Middle East were, in addition, even cheaper than our own. Second, it was assumed that technological change would always keep ahead of resource depletion, so that both new sources of energy, and improved methods of extracting energy from old 
sources would stay ahead of depletion. Third, it was assumed that competition for resource markets would continue to hold costs of resources in a reasonable and historic relationship to their costs of extraction.

Although there have always been pollution, despoilment, and safety problems associated with energy production and use, the negative feedback effect of such costs has been minimal. Negative feedback from pollution did result in the shift from soft to hard coal use in London in the $1890^{\prime} s$, and mining disasters have led to increasingly stringent mining safety regulations. Yet even spectacular mine disasters did little to change the dynamism of the system. obviously degraded quality of air, such as that in Los Angeles after World War II, was amenable to technological fixes with little overall effect.

However, in the early 1970's there appeared serious resource, pollution, and safety constraints that threatened to bring the energy system into a stable equilibrium through the operation of negative feedback. It was not so much the actual situation that produced this check as it was a series of interacting factors that led to new prognoses of the energy situation. Since energy related decisions must be made well ahead of the time of energy use, it will often be the image of a developing future as suggested by current events rather than those current events themselves that are decisive. For this reason the social impact of fusion power at some future time will depend largely on the impact of experience with fusion and its alternatives as projected by that era into its own future.

It is instructive, then, to note what has caused negative feedback from energy production and use to suddenly become a critical part of the discussion of energy issues in the early 1970 's. First is the deeper and deeper penetration of environmental concerns into the American consciousness and the actual decision-making process. This is due both to a shift in the number of people in different cultural subgroups, and therefore to a shift in the importance of certain values (e.g. aesthetics) in the whole society, and to a change among most cultural subgroups in the perceived state of the environment in terms of stable values (e.g. health).

Given these concerns, most uses of energy are likely to become more expensive, and in some cases to require additional energy to mitigate their negative effects. Planning is a small added expense, but the delay occasioned by the planning process bids fair to build up. Suddenly opposition to new mines or wells, or to new power facilities, to transporting and unloading fuel, or to transmission lines has become endemic in the society. This has been accompanied by a growing opposition to growth that welcomes slowdowns for their own sake irrespective of pollution. ${ }^{34}$ At the same time birth rates have fallen rapidly; future population estimates for the U.S. fall lower and lower, and with unemployment, GNP growth seems to be prepared to join population. Second is the fact that just at that point when the U.S. began to depend heavily on foreign sources for the petroleum needed for additional growth, these foreign 
sources were able to set up a cartel that largely eliminated the control of prices by competition, and which also demonstrated the ability of OAPEC to turn petroleum supplies on and off for political purposes. This immediately forced the U.S. to strive for energy independence. But independence implies either overturning the anti-pollution forces (which few even in government want to do, for they are also affected by anti-growth, or at least anti-pollution, influentials) or concentration on conservation through restricting supply--thereby building in additional negative feedback. Note that for this to succeed ultimately, projections on the growth of energy use will be lowered, fewer energy extraction or producing facilities will be built, and thus restricted energy supply will come in future years to be situation-dependent rather than policy-dependent as it actually is today.

closely connected to this argument however, is the third reason for the recent relative influence of negative feedback, and that is the state of nuclear (fission) power development. There are three interacting reasons: lagging development of new technologies, increased concern with steady-state pollution by the technologies in existence and under development, undiminished concern with the safety of these technologies in spite of a very good record of actual safety, and the scarcity of inexpensive capital combined with inflating project costs. 0f course, these impediments interact; fear of pollution and accident continually push up standards and costs for both developed and developing technologies, and put further drain on available capital. The rapidly changing legal and cost environment has also made utilities hesitant to venture upon projects for which insurmountable obstacles may be raised in the future.

It is important to realize that the problem of nuclear safety is exacerbated by the long background of frightening discussions of nuclear weapons and their blast, fallout and other effects, together with the continual drum of well-publicized scientific doubts of the safety of nuclear power plants. (We are not saying the doubts aren't justifed, just that the public is bound to be affected by what has been quite unusual attention to the dangers of this technology.)

THE SOCIAL IMPACT OF FUSION: GENERAL CONSIDERATIONS

Therefore, energy consumption will not grow at rates projected in the recent past. In terms of the objective international and internal situation and the concerns that are being voiced today, the "technical fix" projection of the Ford Foundation's Energy Policy Project seems most likely. ${ }^{35}$ While the more extreme versions of these concerns will be rejected, their kernel of truth will have an effect in a society affluent enough to be deeply affected by the aesthetic and health arguments, as is American society. The Ford study suggests that with attainable conservation policies a doubling of total energy use between the 1960's and the year 2000 could be achieved with a steady improvement in the standard of living. Alternatively, we can assume that this result stems from a combination of lower economic and population growth rates than assumed in previous projections, modest conservation, and some 1 ife-style changes. 
In order to analyze fusion in this context of energy use, we could begin by analyzing all possible comparisons among the technologies in Table 1 . However, we will restrict the analysis to the key comparisons between ideal types $A$ and $C, B$ and $C$, and $C$ and $D$.

In the first scenario, after fusion systems of ideal type $C$ (Table 1) have developed first commercial application in the year 2010, they will begin to displace technologies of ideal type A. While initially this power may be somewhat expensive, projections will confidently show that costs will soon fall below those of fossil/fission dominated technologies both because of improved design and because of the rising costs of fuel procurement for type A. The rapid introduction of fusion power will also be supported by influentials increasingly concerned with resource depletion and the exponential growth in despoliation this is leaving in its wake. There will also be recurrent concern over the hazards of nuclear materials, their transportation and disposal, concerns that fusion systems do not evoke to the same degree. Fusion is attractive to the industry because of the chance it offers of a future context filled with less controversy and more orderly development than has accompanied the development of fission technology or the widespread mining of fossil fuels. Political leaders will be anxious to proceed with the installation of fusion power for these reasons, and the additional reason that rapid introduction will justify the billions of dollars that will have been spent on fusion R\&D by the year 2000 . This will bring personal support and power to them, and through this raise the public's confidence in the system in general, and in science upon which this confidence has been built.

In a scenario comparing ideal types $B$ and $C$, we imagine an energy situation in which fairly high priced energy is produced and handled under careful supervision. The extent to which breeder reactors are considered safe by the year 2010 will depend in part on the public's experience with fission technologies of all kinds. Have there been peace-time catastrophes by then? Given the record, one suspects that a Texas City size ${ }^{36}$ nuclear disaster would be enough in the projected context of constrained energy use to severely cripple future dependence on fission systems of any kind, and particularly those of the technology involved in the tragedy.

The effect of such a curtailment on the support of fusion power is difficult to assess. Fusion power may be a much desired alternative after such an event, or may be seen as just another form of nuclear power with equivalent dangers. The public's opinion will depend a great deal on the position of the majority of the relevant influentials. (We know, for example, that when influentials turned against U.S. participation in the Vietnam war, effective U.S, participation became impossible.) One would imagine that they would convince the public of the differences between fusion and fission reactors, for they will have had many years to learn the technical details, and their desire to de-emphasize fission systems will make them emphasize the value of fusion power ${ }^{37}$--unless a third choice has by then become practical. The position of some key influentials will be not as favorable and their ability to influence the public considerably less, however, if there grows out of the problems of fission technology a general feeling that the government and its nuclear scientists cannot be trusted. In this case, assurance from 
these sources that fusion has few of the problems of fission may fall on unreceptive ears. However, even if fission energy production preserves into the twenty-first century its enviable pollution and safety record, there probably will have been enough incidents and sufficient pollution to maintain concern, particularly in regard to disposal and unauthorized use.

Therefore, if breeder programs such as the LMFBR are the chief competitor of fusion in A.D. 2010, this record will have been achieved at considerable expense. As a result projected fusion power costs may be considerably lower than those of breeder reactors, particularly in the longer run. The influentials will probably also prefer fusion because even a safe breeder reactor program will produce nuclear wastes that must be stored for millennia. They may argue with some conviction that placing such a potential load on future generations passes beyond acceptable moral limits.

A third scenario compares ideal type $C$ with type 0 , or, in other words, the hypothetical first and second generation plants. Second generation fusion power will be, and will be perceived to be, ${ }^{38}$ advantageous from the pollution, hazard, and safety points of view, al though the extent to which this advantage may be perceived will depend on technical details of the alternatives at the time, and the energy history of the intervening years. One of the major reasons influentials and the industry will promote either fusion or advanced solar systems is their hope of speeding up the achievement of systems that by definition have no direct disadvantages.

Costs are very low because fuel is free, and little must be spent to control hazards and direct pollution, although there will still be some minimal despoliation. Essentially, this issue becomes one of the self-control, or indirect pollution and despoliation through the provision of "too much" low cost energy.

These judgments rely on suppositions about the state and average rate and direction of change in American culture relative to consumption, energy use, and aesthetics twenty-five or more years ahead (see the discussion of American culture below). But a humanistic, non-scientific evaluation needs to be added. In these terms, it may be desirable to establish decision rules in economic development that emphasize alternatives with lower intrinsic hazard and pollution potential, even in those cases where a good case can be made for the feasibility of engineering intrinsically less desirable systems to have high safety and low pollution characteristics. Such a conservative decision rule is preferable for several reasons. First, we want to build in as few problems as possible for future generations. Secondly, the more complex the control systems, the more controlled the society. While handling the problems of breeder reactor safety and material transport would not be overwhelming in themselves, ${ }^{39}$ it is necessary to remember that there will be many other problems in the future requiring increased surveillance and control, and cumulatively this is not a probiem area we would want energy systems to contribute to, unless they absolutely must. Most analysts will also prefer systems that despoil the land and use non-renewable resources as little as possible. This suggests a decision rule 
that we set limits on the degree each generation impairs the heritage it passes on. (Of course, in other ways increased energy use and higher technology will increase the heritage, but by our humanistic standard we would avoid the presumption that we know how to trade-off future gains and losses.) In this discussion it is assumed that people in the Year 2000 will have some of the values we have expressed, but here we wish only to suggest what we regard as desirable decision rules without presuming what a majority may or may not want to do in the future. The development of fusion power alternatives will mean that society will again have the opportunity to have at its disposal relatively cheap, abundant, and problem-free energy. This will be directly against the interest of those who have seen the turndown of energy growth rates as a godsend from the ecological and spiritual point of view. And if their appeal has been successful in the interim, they will have a considerable following.

Since the major social argument against an unlimited energy source such as alternates fusion or mixed solar is the manner in which it would encourage almost unlimited growth, ${ }^{40}$ we should consider both the objective and ideological components of the argument. Objectively, pollution through energy use results from the production of energy, including processes of mining, transportation, generation, and transmission, and from those activities and products made possible by the use of energy. If energy were more expensive there would be fewer aluminum throw-away cans, fewer parking lots, fewer planes roaring overhead. Going further, while population growth is not directly tied to economic growth, in industrialized countries it is associated with positive changes in economic expectations, and inversely related to stability or downturn in such expectations. 41 Therefore, it would not be unreasonable to fear that a new source of low cost energy would trigger economic expansion and renewed population growth, with a consequent decline in quality of life from certain perspectives. It is also true that the direct resource conservation resulting from fusion power would be more than cancelled by the increased rate of raw material exhaustion, particularly in the U.S., that would result from plentiful supplies of low cost fusion power. And finally, cheap fusion energy may allow an increasing rate of energy use that would hasten the day when the overall thermal load on local, regional, and ultimately world environments would have worrisome consequences. This is a fact the public would not immediately note, but which would concern influentials. They should also note that artificially halting growth for the reasons advanced here will be hard to sell politically, and if sold will represent a perceived diminution of individual freedom--a diminution that is not perceived when inability to achieve a higher material level is due to natural constraints and the level of economic or technological progress. 42

In assessing the social impact of low cost fusion energy, a humanistic evaluation should also consider the injustice buried in the no-growth argument. 43 For the no-growth philosophy can be seen on the national level as an attempt, by those upper and middle classes that have what they want, to freeze conditions to their advantage. Internationally much the same can be said for the relation of weal thy nations to poorer states, a point well brought out by the third world hostility to the no-growth philosophy expressed at the Stockholm United Nations Conference on the environment in 1972. ${ }^{44}$ Lack of growth in the industrial lands will make development in 
many countries more difficult through depressing markets. And cutting down on goods production in our own society will tend to maintain high levels of unempioyment, especially among the poor. There are ways to avoid these consequences of no-growth, but they are likely to result in developing a larger dependent population, a larger bureaucracy, or both.

In this report, we will not reach a "balance" between arguments for or against low cost fusion power. But we do believe that there is an ideal way to use and regulate even low cost power to maximize its advantages and minimize its disadvantages. Given this, the arguments for and against low cost power probably cancel one another, leaving fusion to be preferred because of its possible advantages in safety, and at least long-term advantages in not directly adding to the pollution load of the environment. But treated thoughtlessly as an essentially free good, fusion power (as well as the mixed solar alternate) could have cumulative effects more disastrous in the long run than more dangerous, polluting, and expensive energy sources.

\section{SPECIFIC ARGUMENTS}

To this point the most general interactions of energy decisions as suggested by Figure 2 have been considered. In order to deepen our understanding we would need to analyze and discuss the characteristics of each box, the non-interactive changes that are occurring in those boxes that develop immanently irrespective of the system, and the interactive relations between changes in each box and all others both directly or indirectly. However, instead of embarking on this exceedingly lengthy task, we will confine the discussion to certain specific arguments about the nature of the factors or their interrelations.

1. The first specific argument considers a scenario for the relation in the interactive diagram between prospective fusion power and future national security. In developing this argument we must remember that extrapolating U.S. national security needs far into the future is most perilous. ${ }^{45}$ We must be satisfied to treat the international future in highly schematic terms, and with reference to issues of today that may or may not have their counterparts after the turn of the century.

Current projections suggest that there will be an intense international demand for fossil fuels, and this demand will cause high prices and more and more emphasis to be put on alternative resources. If we assume little change in our political interests, this suggests that in A.D. 2010 the United States will also be allied to industrialized countries that lack or have exhausted fossil fuel reserves, and will have political commitments such as the defense of Europe and Israel. This will increase the political leverage of those states with remaining petroleum or other fossil resources. In this case, the nonparticularized or biosocial expectation is that each country will pursue its own economic and political interests. U.S. power will remain large, but it will be difficult to use effectively in bargaining or application because of the danger of blocking by other states leading to nuclear war, and the danger of 
high costs in men and material in more moderate wars. Moreover, we assume that culturally there has been a continued increase in pacifism, or disinterest in risking life to attain national goals, in the country since World War II (a disinterest heightened by education, the low status of the military, and the bitter taste of the Korean and Vietnam experiences). The United States doesn't see itself defending its economic position by force, although it continues to see itself as helping allies and poor countries when they are in difficult straits. It sees itself as a powerful, wealthy country that has led and must continue to lead, as the bastion of freedom, and as the leader in technology.

What then are the opportunities and dangers? There is a danger of ever-rising energy prices due to the continued necessity of industrialized democracies to import petroleum if they are to maintain publicly demanded employment and growth levels. In crisis this problem can be further aggravated by threats of a petroleum cut-off by exporters, thus coercing the abandonment of threatened allies such as Israel in 1975. If we withdraw support from such allies, this may excite aggressors to attack them.

Given the projected international and energy situation, and the projected evolution of relevant aspects of American culture, an active international policy would require the United States to emphasize energy research and development, large capital outlays for power plants and other energy related fields, and a national program of energy conservation. Washington would try to encourage its allies to do the same, and to stand up to opponents in crisis. In exchange we would increase U.S. technical assistance and guarantee energy supplies in future crises when possible, and continue to give political and military aid to threatened states, thereby maintaining our international role (but also our exposure to blackmai1).

At the final or humanistic assessment level, what should guide U.S. energy/international policy in terms of a specified set of goods (or values)? We might specify these goods as a reasonable balance of overall utilities, the distribution of these utilities, the transcendence of material societal interests, and avoidance of immoral actions, such as the deliberate starvation of underdeveloped countries or the nuclear destruction of enemies. 46 It seems clear in the 1 ight of these goods that the achievement of inexpensive fusion power will be highly desirable at an early point. Low cost domestic power would give the U.S. a freer hand internationally at the same time that it would reduce the temptation to use violence to resolve critical energy shortfalls for ourselves or our allies. This ability would in turn stabilize the position of leaders in our country, and prospectively could be seen by them as having this effect.

Thus, consideration of international interactions produces a specific argument that gives added weight to the generalized argument for emphasis on fusion power rather than ideal types $A$ or $B$. The argument could, of course, become turned around if fusion technology becomes dependent on construction materials concentrated in countries with fundamentally different interests than our own. 47 
2. A second specific argument concerns the relation between the public, influentials, energy industry leaders, and political leaders on the one hand, and energy decisions and subsequent consumption, on the other. In our model (Figure 2) we assume that each of the four energy related groups has its own interests: for the industry it is profit and continued control, for political leaders it is continuation in office, for influentials it is maintenance of their position vis-à-vis government, public and the industry (as well as in a variety of influential subcultures with rules and standards of their own), and for the public it is the full range of benefits and costs associated with energy. 48

In this situation the public will be the passive actor, but yet the most important, for in the end public judgment will be decisive. In general most leaders of the energy industry or government will prefer to keep outside influentials and the public out of the energy decision process, for they have quite enough internal interests to satisfy within their own networks of bureaucratic and client relations. ${ }^{49}$ (There are, however, always exceptions, persons who will feel it to their personal or corporate advantage to use outsiders to provide leverage for preferred policies.) However, if influentials and the public come to be seriously involved, then political leaders will want the whole public--as expressed for example through regular elections--to be involved, rather than particular individuals or pressure groups, for the values and interests of the whole public are more similar to those of industry and government than are those of special groups. ${ }^{50}$ Such leaders rose to leadership partially on the basis of value congruency with the public--although this was in the past and on other issues. In the case of energy questions for the rest of this century, industrial and political leaders will have to set satisfying the whole public most of the time as their goal whether their object is to keep the public out of the details of decision, or to have a sympathetic public base of support in opposition to special pressures.

In saying this, it is necessary to dispose of two kind of arguments. The first, associated in recent years with the name of Graham Allison, is that there has been a mistaken over-emphasis in analysis of decision making on the "rational actor model" of an enlightened decision maker working in the public interest. 51 Allison suggests that emphasis should be placed on the determinants of "organizational process" or "bureaucratic politics." The thought is simply that our analytic focus should be less on the external analysis, action, and feedback network than on internal bureaucratic requirements, such as the need to satisfy the special interests of all of the minor earldoms and duchies that form any great bureaucracy. 0bviously both approaches are important, particularly in the details of policy and policy implementation. However, since in a democracy the attitude of the public and of those who influence the public is the real world, there are narrow limits on the degree to which the struggle of internal bureaucracies can deflect a decision maker from serving the public interest as he understands it, or as he believes the public understands it. Even though a bureaucracy would be happiest with decision $X$, if $X$ appears likely to have disastrous consequences, a decision maker will not make it. He will try to mollify the bureaucracy, but will not decide in their favor. One reason he is free to do this is that on closer inspection all bureaucracies consist of many 
subgroups competing for the long-term favor of political leaders and their publics. The bureaucrats in these subgroups must struggle in terms of ideas as well as subgroup power, and come up with plans or actions that are likely to produce results in any area where executive or public attention remains focused. If they do not, the individual leaders of the subgroups are in political danger and they know it.

The alternative Marxist analysis is that energy policy in a capitalist system is made by the capitalist class--in this case, the energy industry and the political leaders--with no more than casmetic regard for the interests of the people. To a degree an alliance of the leaders of the energy industry and the governmental regulatory agencies does, of course, exist--and analogous relationships of government and industry may be found in all parts of the economy. But in a democracy with the range of civil and political rights of the United States, and the range of alternative support for influentials that is available, there are reasonably tight limits on the degree to which this special interest alliance can warp policy without danger to itself. The dangers include the replacement of public officials by others more responsive, increased government regulation, or even the replacement of private power by public (or viceversa). If this were not so, we would not have the low rate structure and high availability of power that we have relative to other countries with a variety of social systems. ${ }^{52}$

Therefore, we conclude in this special argument that it is not unrealistic to regard American society as a unit with identifiable interests as we have in the foregoing general argument. It also supports the assumption that for issues of critical public interest, the opinion of the public will in the end be decisive. It does not, however, go far toward resolving the question of how a governiment or industry might best proceed in fusion power plant research and development so that the public could make an informed choice among the priorities to be accorded alternative energy systems, and later among alternative fusion power systems. In view of the problems that have arisen in the course of the development of fission energy, this is clearly an area deserving further analytic attention.

3. A third specific argwont might detail the historic nature of American culture, and the likelihood of fundamental change in American culture, in terms of current trends and a biosocial understanding of cultural variability. The aspect of culture that is most critical to the analysis is the expected continued priority of the material consumption patterns made possible by inexpensive energy relative to other values.

American society has long been accused of overemphasis on material production. Yet several modifications need to be made to the general proposition. First, there is evidence that American materialism is primarily a universal (therefore biosocial) desire of all men when conditions make it possible. For example, the flood of immigration into the country until it was cut off in the 1920's was primarily due to a desire for higher standards of material iiving-al though some did come for the greater civil freedoms that we allowed. The rapid economic 
development of Asian or African societies when it became possible indicates much the same. Secondly, America has always had a strong elite countercurrent that damned the material world in favor of the spiritual. This was the original Puritan message, and that of pietist groups such as the Amish. After a long decline from the seventeenth century, anti-materialism had a considerable revival in the mid-nineteenth century, especially around Boston. ${ }^{53}$ After its collapse following the Civil War, this critique has gradually made another come back, until anti-materialism again became a dominant elite theme in the 1960's and 1970's.

A third modification is that material values have never had higher priority than those for individual or family survival and happiness in the minds of most Americans. Many Americans may have been misled into thinking material goods would bring health or happiness when they would not--e.g. patent medicines. But this was a matter of faulty information rather than value priority. What most Americans, and perhaps most peoples in the mass, have done is to value consumer goods over the standards of clean air, education, or environmental beauty that some influentials would prefer. Yet even here, Americans would give up the material goods if the choice were no schools or unbreathable air. ${ }^{54}$

We suspect that the end result of the influential and elite interest in anti-materialism in recent years will be to moderately support the upward trend of taste and intellectual interests that has resulted from universal education extending to the college level, and from more experience with higher consumption levels. In the future people will not accept as much ugliness, noise, smog, or danger at work or home as they have in the recent past. But they will still be materialists within these limits, and will be most reluctant to give up personal transportation, frost-free refrigerators, or air conditioning.

This is not to say that people could not be forced to give these up by crisis or the fiat of authoritarian rule. Nor is it to say that the time is not ripe for new faiths, with old renunciations of the flesh. This occurred at the end of the Roman Empire, when the brightest and the best went off to the monastery. This withdrawal could happen again, but it would not significantly affect this analysis as long as we are a democracy. For if the public had had the vote in the fifth century, it would probably have opted for more low-cost energy, even while its brightest went off to the monastery.

The most general remark about the interaction of culture with the energy question is that cultures of whole peoples change slowly. Expectations of high income and growth die slowly, but once dead will revive slowly. Thus, if energy crises continue over a considerable period, they will reduce demand, and lower demand will gradually become a part of the pattern of expectations. While an energy policy to achieve a high growth rate might be given top priority in 1976, after a decade of economic stagnation a policy to attain this same growth rate would be given a lowered priority, for the culture would have shifted to lowered expectations by 1986 . 
The result we draw is that a reasonable extrapolation of recent cultural trends will increase moderately but not decisively the public's perception of the importance of threats to the natural environment relative to threats to consumption goais as a consequence of energy decisions. Low-cost power will be desired within limits of safety, pollution, and aesthetic standards only slightly more restrictive than those of 1975. However, a more important influence than trends in the verbal culture will be those changes in the material expectations of the public, reflected in the level of their demand for improved energy supply, that are occasioned by the history of energy availability between 1975 and 2010 .

\section{CONCLUSIONS}

We conclude that the direct effects of an ideal form of fusion technologies would be socially more desirable than those of the alternatives. This is particularly true of the second generation fusion power plant. However, given our technological inputs, this was a trivial result. Less trivial was consideration of the negative effects that might accrue through the availability of potentially unlimited supplies of low cost energy. It is concluded that while there may be reasonable humanist argument both for and against such abundance, in a democratic society control of energy development for its own sake is likely to be unacceptable. However, if the indirect effects of pollution, despoilment, and resource depletion through ever expanding energy use become sufficiently disturbing to the well-being of the majority, unlimited energy may come to be seen as undesirable by the society. To this extent successful research and development for unlimited sources such as the fusion or mixed solar alternatives might be judged from some point far in the future to have been a mistake. This could occur even though advances in the technology of pollution control and resource use greatly reduce the pollution and hazard accompanying a much higher rate of energy utilization.

\section{RESEARCH REQUIRED}

It seems desirable for further research and development to precede any more detailed macro- or micro-analysis of social impacts. However, as an input to the setting of research and development policy the comparative social desirability of the full range of energy technologies including fusion power plants might be periodically addressed by this social impact methodology. In preparation for such periodic evaluations, a detailed study should be made in the near future to determine and evaluate the sources of public concern over specific aspects of fission and fusion technology. Indeed, this approach, or one analogous to it, seems to be an essential precursor to the development of an acceptable national energy policy. It is important to note that at this stage of development the fusion power system is often treated most favorably by a wide variety of influentials. If in engineering terms further R\&D shows fusion energy to be an area in which 
the nation should invest major resources, it will still remain a challenge for industry and government to so structure the fusion development program that this "favorable press" is maintained. It may well be that early analysis of alternative research and development policies from this perspective would help to avoid some of the pitfalls that have beset the development of fission energy in this country. Needless to say, the problems addressed by such an analysis would go far beyond those of public information policy. 


\section{FOOTNOTES}

1. "Modular Integrated Utility System (MIUS) Program Description," Office of Research and Technology, U.S. Department of Housing and Urban Development, December 1972. Adoption of such a system might entail significant changes in the provision of infrastructure at the local level, but it would also reduce the number of large, central station power plants needed in the future, especially if applied to the requirements of the commercial and industrial sectors in addition to the residential sector. Another recent study concludes that there is significant potential for both industrial cogeneration of process steam and electricity as well as joint ventures between industry and electric utilities to build dual-purpose central power stations from which industry would receive power and steam. See conclusions of Energy Industrial Center Study, Dow Chemical Company, for the National Science Foundation, June 1975.

2. WASH-1535, Proposed Final Environmental Statement, LMFBR, Dec. 1974, I, pp. 1.10-1-2.

3. See "The Economics of Nuclear Power," Technology Review 77, 4 (1975).

4. Some believe eventually this alternative might include the conversion of solar energy to electricity in space by power plants built by space colonies. Articles on this topic have appeared in Physics Today (9-74), The CoEvolution Quarterly (Fall 1975 and Spring 1976), The New Scientist, Science, The New York Times Magazine, and others.

5. Ibid., Cf. p. 6A 5-18 with p. 6A 1-191.

6. Cf. Weber's use of ideal-types (Max Weber, The Theory of Social and Economic Organization (New York: Free Press, 1964) (in recent translation), esp. T. Parson's introduction, pp. 8-29.

7. See Jim Hartley, "Materials Availability for Fusion Power Plant Construction," BNWL-2016 in this series.

8. This paragraph is based on Martin V. Jones, A Technology Assessment Methodology, I, (The Mitre Corporation, June 1971), pp. 40, 46, 67, 82. See also Joseph F. Coates, "Technology Assessment," The Futurist, (Dec. 1971), pp. 227-231. See also Appendix I.

9. WASH-1535, Proposed Final Environmental Statement, LMFBR, II (5) and III (6), 6A.1.6, and other sections.

10. The following analytic framework is based on R. D. Gastil, "A General Framework for Social Science," Policy Sciences 3 (1972), pp. 385-403; and R. D. Gastil, "The Determinants of Human Behavior," American Anthropologist 63 (1961), pp. 1281-1291. 
11. For the argument for this separation see R. D. Gastil, "Social Humanities," Policy Sciences 5 (1974), pp. 1-14. In particular, discussions of energy issues of ten mix scientific and non-scientific judgment in regard to energy issues (e.g. Jean Johnson, "Societal and Political Implications of the Energy Crisis" [Arlington, Virginia: Forecasting International, 1974], or Transition [Salem, Oregon: Office of Energy Research and Planning of the State of Oregon, 1975]).

12. For a consideration of these criteria see R. D. Gastil, "Beyond a Theory of Justice," Ethics 85, 3 (April 1975), pp. 183-194.

13. The reader should note the difference between ideological interest groups and special interest groups as ordinarily defined. The latter are usually seen in terms of material interests, and in this sense the energy industry, or parts of it, would be critical special interest groups.

14. See Robert Dahl, A Preface to Democratic Theory (Chicago: University of Chicago Press, 1956), pp. 48-49, 90-123.

15. See R. D. Gastil, "Kuhn's 'The Logic of Social Systems': The Rational First Approximation as Social Science," Pol icy Sciences 6 (1975), pp. 467-479. The following approach is heavily dependent on Alfred Kuhn's work as presented in The Logic of Social Systems (San Francisco: Jossey-Bass, 1974) and Unified Social Science (Homewood, Illinois: Dorsey, 1975). This is a more extensive but similar approach to that of George Homans (Social Behavior: Its Elementary Forms, and The Nature of Social Science) and Peter Blau (Exchange and Power in Social Life).

16. For example, Paul Samuelson, Economics, Sixth Edition (New York: McGraw Hill, 1964), pp. 56-76.

17. Bernard Berelson and Gary Steiner, Human Behavior: An Inventory of Scientific Findings (New York: Harcourt, Brace and World, 1967), p. 562.

18. William Ittelson, et al., An Introduction to Environmental Psychology (New York: Holt, Rinehart and Winston, 1974), pp. 303-338. Also, Gardner Lindsay and Elliot Aronson (eds.), The Handbook of Social Psychology, 2nd ed., III, pp. 856-903. In regard to energy see Todd La Porte and Daniel Metlay, "They watch and Wonder: Public Attitudes toward advanced Technology," (Berkeley, California: Institute of Governmental Studies, Dec., 1975), especially pp. 181-206.

19. See Chauncey Starr, "Benefit-Cost Studies in Sociotechnical Systems," pp. 17-42, and Lester Lave, "Risk, Safety and the Role of Government," pp. 96-108, both in National Academy of Engineering, Perspectives on Benefit-Risk Decision Making (Washington, D.C., 1972). 
20. Lindsay and Aronson, The Handbook of Social Psychology, I, pp. 758-759.

21. Kuhn, Logic of Social Systems, pp. 288-427.

22. See P. A. Sorokin, Social and Cultural Mobility (Glencoe, I1l.: Free Press, 1959), pp. 559ff.; Francis R. Allen, Socio-cultural Dynamics (New York: MacMi1lan, 1971), pp. 288-300.

23. For example, in 1966 a study of smokers showed $91 \%$ realized the danger of smoking to health. (John Tamarin and Harvey Resnik, "Risk Taken by Individual Option," in National Academy of Engineering, Perspectives on Benefit-Risk Decision Making, 1972, pp. 78-84 (80). More generally see La Porte and Metlay, "They Watch and Wonder:", op. cit., especially pages $153,189-90$.

24. Ibid. See also Everett Rogers, Diffusion of Innovations (New York: Free Press, 1967), and Amitai Etzioni, The Active Society (New York: Free Press, 1968), pp. 182-190.

25. See Berelson and Steiner, pp. 536-543. On the gap between influentials and public see Frank Armbruster, The Forgotten Americans (New Rochelle: Arlington House, 1972). La Porte and Metlay ("They Watch and Wonder," op. cit.) point specifically to the public's preference for factural information (p. 111), and also support the hypothesis of value stability and somewhat greater mass materialism (especially pp. 78, 95, and 260).

26. Cf. Berelson and Steiner, p. 190. Also Leo Weisgerber, Von Weltbild der deutschen Sprache, 2nd ed. (Düsseldorf, 1954). A possible analogy to the difficulty of distinguishing between fission and fusion power is that of the French difficulty of distinguishing between conscience and consciousness, a conceptual lag that held back the acceptance of Freud in France for at least a generation. See Ruth Lindemann, Der Begriff der Conscience in fränzösischen Denken (Jona and Leipzig, 1938), esp. pp. 109-115. On rigidity and simplification of thinking under stress and fear, see David Krech and Richard Crutchfield, Theory and Problems of Social Psychology (New York: McGraw Hi11, 1948), esp. p. 141; El ton McNeil (ed.), The Nature of Human Conflict (Englewood Cliffs: Prentice-Ha11, 1965), pp. $45-63,155-171$.

27. In addition to Kuhn, Logic of Social Systems, pp. 330-353, see Etzioni, The Active Society, pp. 103ff., and Lindsay, Handbook of Social Psychology, V, pp. 576-577. As Herbert Roback says, "Political appeal is measured by public acceptance . . . . when President Kennedy announced this goal (lunar landing) in 1961, it was well received in the Congress, and it struck the public's imagination, particularly since the hurt of Sputnik was still felt acutely in the body politic. If the moon project were announced today rather than ten years ago, and a price tag of $\$ 25$ billion were put upon the enterprise, it would be shelved by a Congress sensitive to public disenchantment with costly ventures that have no 
apparent value for solving the prosaic but pressing problems of everyday life." ("Politics and Expertise in Policy Making," in National Academy of Engineering, Perspectives on Benefit-Risk Decision Making, pp. 121-133 [124-125]).

28. See also Anthony Downs, "Up and Down with Ecology--The Issue-Attention Cycle," Public Interest 28 (Summer 1972), pp. 38-50.

29. Ibid.

30. See definition of influentials (above); also Etzioni, The Active Society, op. cit.

31. On underdeveloped countries see W. Arthur Lewis, Theory of Economic Growth (London: Allen and Unwin, 1955). Consult any series of polls on the concerns of industrialized countries.

32. For example, at least in regard to small groups Berelson and Steiner conclude "Normally, the leader is better able to affect the group's means than its goals," (Human Behavior, p. 343). People listen to those who agree with them, and the more interested they are in the subject the more this is true (Human Behavior, pp. 529ff.). The reason why this must be so in all communication is analyzed by Kuhn, The Logic of Social Systems, pp. $157 \mathrm{ff}$.

33. The terms "positive- and negative- feedback" are, of course, always to be understood in the technical systems sense, and do not imply value judgments.

34. The thinking, e.g., of Karl Hess, "Principles of Lifestyles," in Anton Schmalz (ed.), Energy: Today's Choices, Tomorrow's Opportunities (Washington, D.C.: World Future Society, 1975), pp. 177-183. Charles Reich, Gary Snyder, and many other popular influentials express similar thinking.

35. A Time to Choose: America's Energy Future, Energy Policy Project of the Ford Foundation (Ballinger Publishing Co., 1974), pp. 45-79.

36. About 500 killed by Ammonium Nitrate ship explosion in 1947. (Newsweek, April 28, 1947, pp. 29-32. Business Week, April 16, 1948, pp. 42ff.)

37. At present the scientific wing of the ecological establishment is hopeful but cautious. For example, Amory Lovins (World Energy Strategies [New York: Friends of the Earth, 1975], p. 75 and note) writes: "The theoretical biological significance of these products (of CTR) may be... an order of magnitude smaller than from fission reactors... Unless it is many orders of magnitude smaller than that--which is possible but not yet plausible--fusion does not represent an attractive long-term energy source, though in the medium term it is certainly preferable to fission." 
38. Cf. ibid., note 44 , where the advantages of the second generation system are accepted explicitly.

39. WASH-1535, Proposed Final Environmental Statement LMFBR, December 1974, I, pp. 1.10-1-2, and other sections.

40. This is the final argument of one writer, Lovins (op. cit.) against fusion. He writes: "One could argue further that if fusion turned out to be a clean, cheap, and safe energy source, man would lack the discipline so to manage it as to prevent serious ecological and climatic damage. Recent history does not say much for man's responsibility in managing large stocks of energy."

41. See, e.g., Richard A. Easterlin, "On the Relation of Economic Factors to Recent and Projected Fertility Changes," paper presented at the 1965 meeting of the Population Association of America. Also Ronald Freedman, Pascal Whelpton, and Arthur Campbe11, Family Planning, Sterility and Population Control (McGraw-Hill, 1959).

42. Or as Kuhn puts it, ". . . group decisions made through transaction are more acceptable, other things equal, than those made through a dominant coalition," Unified Social Science, p. 354 .

43. See Hans Joachim Hoffmann-Nowotny, "Soziologische Bemerkungen zu den 'Grenzen des Wachstums '," Schweizer Monatshefte 54, 9 (1974), pp. 628-642.

44. "Declaration on the Third World and The Human Environment," (Stockholm, June 1972). Discussed in ibid.

45. For some possible future scenarios in this area and their difficulties see R. D. Gastil, "A Pair of Related, Pessimistic Scenarios," in H. Kahn and A. Wiener, The Year 2000 Ne: York: Macmillan, 1967), pp. 293-308.

46. See the discussion of humanistic evaluation, pp. 8-10 above.

47. See Gerald Kulcinski, "Fusion Power--An Assessment of its Potential Impact in the USA," Energy Policy (June 1974), pp. 104-125 (112-115). See also Jim Hartley, "Materials Avail ability for Fusion Power Plant Construction," BNWL 2016 in this series.

48. For the reasonableness of these assumptions as a first approximation see R. D. Gastir, "The Logic of Social Science as First Approximation," Policy Sciences (forthcoming, 1975).

49. In addition to Allison, op. cit., see Etzioni, The Active Society, pp. 163ff. 
50. For the discussion of evidence from polls see Armbruster, The Forgotten Americans. This would also follow from the theory of democracy.

51. Graham Allison, Essence of Decision: Explaining the Cuban Missile Crisis (Boston: Little Brown, 1971).

52. See Philip Sporn, The Social Organization of Electric Power Supply in Modern Societies (Cambridge: M.I.T. Press, 1971).

53. See Van Wyck Brooks, The Flowering of New England: 1815-1965 (New York: Dutton, 1937), pp. 179-202.

54. In their study of public attitudes toward technology and energy La Porte and Metlay describe a public quite able to think in terms of a variety of short and long term concerns (La Porte and Metlay, "They Watch and Wonder," op. cit.). In an appendix (pp. 309-330) the authors also summarize a number of related and largely confirming studies of public attitudes.

55. For example, see: Amory B. Lovins, The Case Against the Breeder Reactor, Bulletin of the Atomic Scientists 29, 3, (March, 1973) pp. 29-35, or: Allen L. Hammond, Breeder Reactors: Marvel or Menace?, 246, 1472, (Harpers, NY January, 1973) pp. 30-34.

56. For example, see: Amory B. Lovins, World Energy Strategies (Friends of the Earth, NY, 1975), or: J. Holdren and P. Herrera, Energy--A Crisis in Power, (a Sierra Club Handbook, Sierra Club, 1971), or: John Goffman, Nuclear Power and Elocide: An Adversary View of New Technology, Bulletin of the Atomic Scientists 27, 7, (September, 1971) pp. 28-32. 
APPENDIXES 
The process followed to develop this analysis included the identification of known energy resources as given in Table Ia, and the development of criteria for analysis of these resources as given in Table Ib. Table Ic offers a qualitative evaluation and comparison of these energy resources and related power technologies in terms of present use, sustainability of supply, ability to meet A.D. 1975-2025 power demand, hazard, environmental impact, aesthetics, and despoilment.

For the purposes of Tables Ib and Ic, sustainability is defined by the resource reserve base in terms of time, roughly, less than several centuries, more than 1000 years, greater than 10,000 years and/or renewable. Ability to meet demand is based on the combination of resource and technological availability. Hazard includes, for example, accidents involving workers only; exposure to low-level radiation; and risk to the public of catastrophic accidents, sabotage, or diversion of radioactive materials. Environmental impact means the degradation of the natural environment due to the effects of pollution on the air, land, water, and biological systems. Aesthetics/despoilment is the impairment of natural beauty in terms of the changes perceived by people (e.g. siting a power plant on a scenic river) and the removal of land from one use by its temporary or permanent use for another (e.g. by covering agricultural land with solar collectors).

Tables Ia, Ib, and Ic were then used to construct the idealized dominant resource/technology alternatives (Table 1 of text) which put the general characteristics in terminology and perspective useful in the social analysis. 
TABLE Ia Energy Resources

A. FOSSIL FUELS

1. OIL

2. NATURAL GAS

3. COAL

4. OIL SHALE

5. TAR SANDS

B. SOLAR-PHYSICAL

1. WIND

2. OCEAN WAVES

3. OCEAN CURRENT

4. OCEAN THERMAL GRADIENT

C. SOLAR-BIOLOGICAL

1. WOOD

2. AGRICULTURAL WASTES

3. ALGAE/BACTERIA AGRICULTURE

D. SOLAR-DIRECT, CONVERSION TO

1. HEAT and/or

2. ELECTRICITY

E. GEOTHERMAL

1. STEAM

2. HOT-ROCK

F. MUNICIPAL REFUSE \& SEWAGE

G. GRAVITY

1. HYDRO (ALSO SOLAR)

2. TIDAL (ALSO LUNAR)

H. RADIOACTIVE

1. URANIUM

2. PLLITONIUM
I. FUSION RESOURCES

1. DEUTERIUM + TRITIUM (LITHIUM)

2. DEUTERIUM + DEUTERIUM

3. DEUTERIUM + HELIUM-3

J. OTHER, EXOTIC

1. GRAVITY WAVES

2. WATER SALINATION

3. OSMOTIC PLIMPS

4. ELECTROSTATIC ENERGY

SOURCES: New Energy Technology--Some Facts and Assessments, H. C. Hottel and J. B. Howard, M.I.T. Press, 1971; and "ENERGY," edited by Medard Gabe1, The CoEvolution Quarterly, Spring 1975, p. 14. 
1. PRESENT-USE (RANK)

2. SUSTAINABILITY, TIME, \& MAGNITUDE

3. TECHNOLOGY
a. STATUS and/or AVAILABILITY
b. EXPECTED ABILITY TO MEET FUTURE DEMAND
c. COMPLEXITY \& RELIABILITY
d. FLLEL CYCLE/PRODUCTION PLANT
1. material requirements
2. size
3. siting
4. efficiency
5. potential for "waste" heat utilization
e. ENERGY STORAGE
f. NET-ENERGY ANALYSIS
g. SUBSTITUTABILITY ALONG RESOURCE TO END-USE CONTINUUM

4. ECONOMICS
a. CAPITAL COSTS (\$ per KWe)
b. OPERATION COSTS ( $\$$ per KWH)
c. UNIT COSTS ( $\$$ per KWH)

5. SAFETY, RISK, \& HAZARD
a. WORKERS \& PUBLIC
b. SPATIAL DISTRIBUTION \& TIME-LAG

6. ENVIRONMENTAL IMPACT
a. FUEL CYCLE \& PRODUCTION PLANT
b. POLLUTION \& DESPOLIATION
c. SPATIAL DISTRIBUTION \& TIME-LAG
d. INDIRECT EFFECTS ON "CARRYING-CAPACITY"*

7. SOCIAL IMPACT
a. ABILITY TO PROVIDE SIGNIFICANT PORTION OF POWER REQUIREMENTS OVER TIME (\# 2 \& 3 )
b. REASONABLE COST ASSUMING STRONG MEASIJRES TO MITIGATE HAZARDS and/or ENVIRONMENTAL IMPACTS (\# 4, 5,\& 6)
c. CAPITAL \& LABOR REQUIREMENTS \& AVAILABILITY
d. COMPLEXITY OF CONTROLLING SOCIAL MECHANISMS IN BOTH THE PUBLIC AND PRIVATE SECTORS
e. CDMPARATIVE QUALITY OF LIFE

\footnotetext{
* That is, on the limits on the number of people or units of GNP in a specific are given fixed technology and values.
} 
TABLE IC Projected Analysis of Energy Resources A.D. 1975-2025

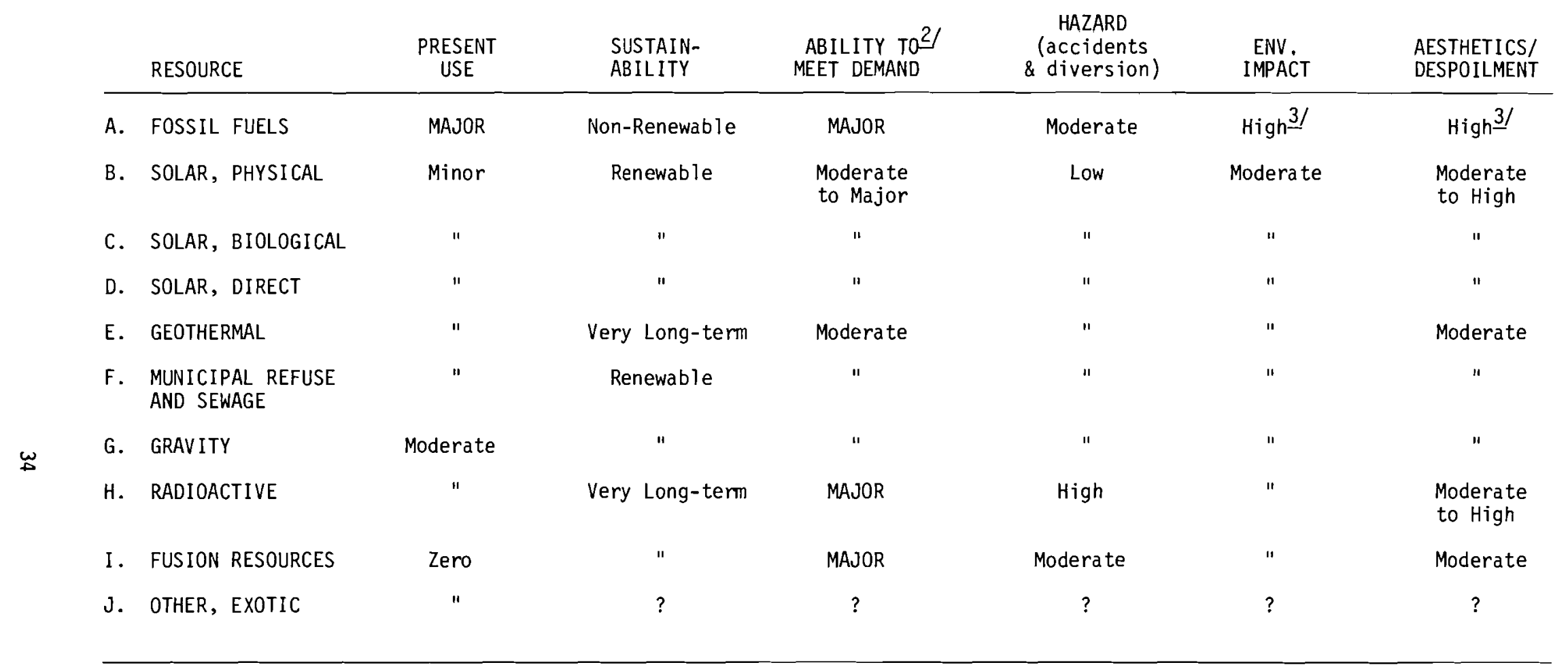
NOTES: I/ Qualitative, not quantitative, evaluation and comparison of energy resources; use in 21 st century will depend
on technological developments and trade-offs between social, economic, and environmental costs and benefits.

2) Energy consumption is dependent on population level, life-style, and natural and social constraints in terms of the balance between material standard of living and quality of life.

3/ At expected levels of use, if fossil fuels are no longer dominant, their impacts will, of course, be reduced. 


\section{APPENDIX II: MICROANALYSIS}

The foregoing report has been concerned with a macro social analysis of an energy resource/technology, and specifically with the comparison of future fusion systems with alternative energy technologies. If on the basis of the macroanalysis the fusion power system becomes the technology of choice (dominant technology) on a national or global basis, then there will remain the problems of microanalysis--i.e., the degree to which fusion power should be dominant in any particular place and the particular sites in which nuclear facilities, transmission lines, and so on should be located. The latter is a type of analysis with which the nuclear research fraternity has become particularly acquainted, and some theory has been developed for its resolution.*

Although we do not propose to discuss this latter range of problems in detail, we do realize that microanalysis is not unconnected to the problem of overall choice among energy systems. For to some degree it will be the decisions that fusion facilities are the best choice for particular power systems, and agreements on suitable sites for establishing facilities for these systems, that will make possible the practical use of the fusion power plant. We believe that because of the lower despoliation and pollution potential of the fusion system, this will not be as critical a constraint for fusion power as it is now for fission, fossil, or hydro facilities. However, the sheer size of fusion facilities and associated transmission requirements may raise significant problems.

In order to get a feel for the interplay of government, energy industry, and the public in the micro-process, we thought it might be useful here to outline the complexity of the decision process at this level on the basis of a study of a local utility. $* *$

Puget Sound Power \& Light Company (PSPL) is the largest investor-owned electric utility in the state of washington. As of the end of 1974, PSPL had 408,856 customers, representing approximately 1.1 million people or $32 \%$ of the state's population. PSPL's average annual revenue per residential customer is about the same as the national average for investor-owned utilities; however, average consumption within PSPL's service area is about double the national average while the cost per KWH is about half the average. Because in the Pacific Northwest a large percentage is derived from hydro-electric facilities whereas very little of energy requirements of the rest of the country are met by hydro-power, we could tentatively conclude that the high average residential consumption of electricity by PSPL's customers is directly related to the availability of low-cost hydro-power. It is interesting to note the possible

* See, e.g., Jacques Gros, et al., "A Systems Analysis Approach to Nuclear Facility Siting," International Institute for Applied Systems Analysis, RM-74-29, December 1974.

** "An Analysis of the Puget Sound Power \& Light Company's Corporate Planning and Management System with Respect to Public Planning Issues," H. Markus, A. Thompson, and G. Thune, University of Washington, June 1975. 
comparability of this situation to a future case where power costs from a system of ideal types (C) or (D) were significantly lower than either ideal types (A) or (B) as given in Table 1 in the text.

The analysis of the corporate planning and management system of PSPL in relation to its environment evolved through four hierarchial systems or levels as shown by Figures IIa and IIb. Each system was analyzed in terms of its components and the flows between these components. The interface or interconnections between levels were identified by the flows from one system to another. Four types of flows were considered significant: (\$) or money flows, (E) or electricity flows, (M) or material flows including natural resources and raw materials through finished goods, and (I) or intelligence and information flows. The systems shown in Figure IIb act as the primary resources and constraints on the corporate planning and management system as shown in Figure IIa, especially in terms of the decision and design space.

Looking at the alternatives given in Table 1 in relation to Figure IIb, we see that the figure is a description of one utility from the Base Case where the dominant resource is hydro-power; alternatives \# $1,3,4, \& 6$ primarily revolve around the relationships between the Public Policy \& Government Regulatory Authority component, the Factors Supply component, and the Production Factors component; alternative \#2 assumes change in the relationship between the End-Use System component (the public) and government; while alternative \#5 would involve changes similar to alternative $\# 3,4, \& 6$ on the one hand and alternative $\# 2$ on the other.

In A.D. 2000, if PSPL and other utilities in the Pacific Northwest region decided to jointly build a first generation fusion power plant, alternative \#4, the process would probably be quite similar to current joint light water reactor projects, especially in terms of the complexity of controlling social mechanisms (Appendix I, Table Ib, 7d). This complexity is well illustrated by the present licensing process for nuclear power plants and the number of federal agencies involved in the regulation of the nuclear fuel cycle and electric-power generation, transmission, and distribution. Such projects are also regulated by state and local governments.

Nuclear power plants are primarily regulated by the U.S. Nuclear Regulatory Commission in addition to local and state control. N.R.C. assumed the responsibilities of the Atomic Energy Commission's regulatory program in accordance with the Energy Reorganization Act of 1974 , Public Law 93-438/93rd Congress/H.R. 11510/10-11-74. N.R.C. reviews utility applications for nuclear power plant 1 icenses and prepares Environmental Impact Statements under the National Environmental Policy Act where the proposed action is administrative; that is, issuance of a construction permit for the proposed facility, monitoring the facility while under construction, and issuing the plant's operating license.

The Energy Facility Siting Council (EFSC) was authorized in 1970 (as amended 1976) by the Washington State Legislature under RCW 80.50. The council is composed of a chairman appointed by the governor, representatives of thirteen state agencies, and a representative from the 


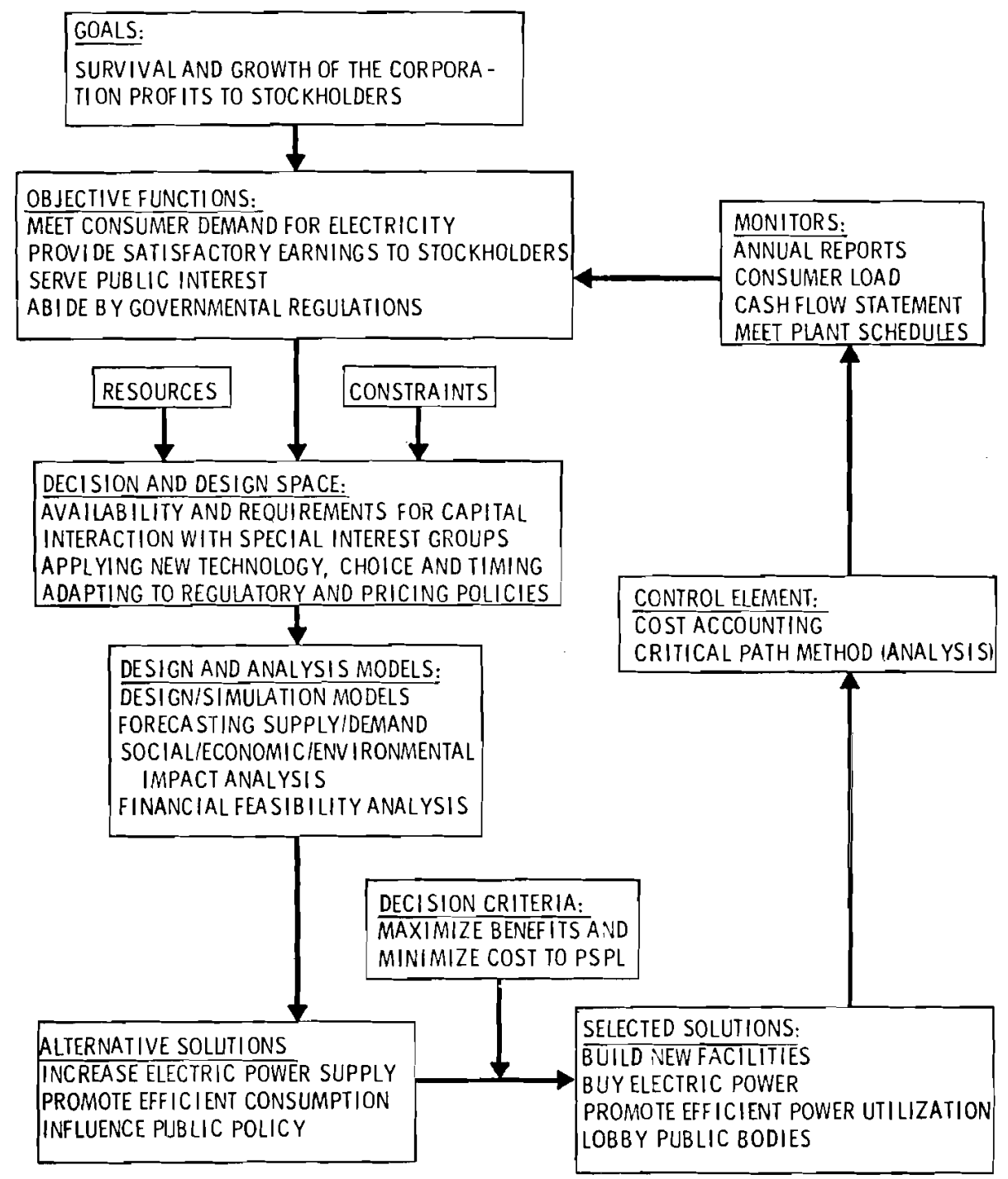

FIGURE IIa PSPL Corporate Planning and Management System

county in which the plant under consideration would be sited. An application is submitted by a utility or group of utilities who wish to build a thermal power plant. The council reviews the application along with the accompanying environmental report, and a recommendation is reported to the governor based on this material and comments received during public hearings. The governor makes the final decision as to whether the state will approve or reject the site certification. EFSC's guidelines for the applicant are given in the Washington Administrative Code, WAC 463.12; the Environmental Report is required under RCW 43.21c, and WAC 463.08 specifies its form and content. Plants built under EFSC's review process are monitored by EFSC after they begin operation to insure compliance with conditions set forth in the certification agreement. 

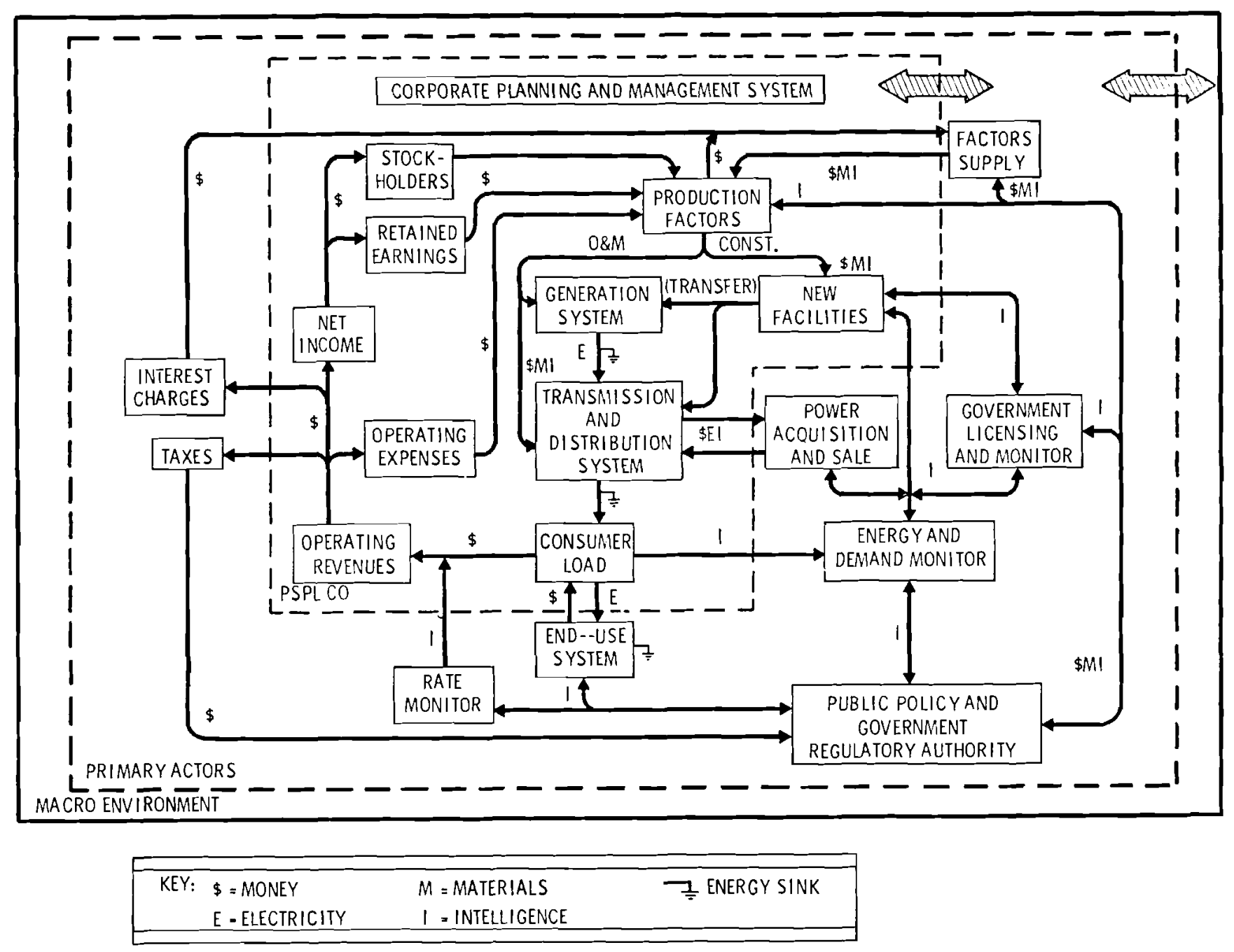

FIGURE IIb Internal Flows and Interconnections Between CPMS/PSPL/PA/ME 
In the state of Washington, the county within which a proposed thermal generating plant is to be located has some clout because RCW 80.50 .090 specifies that EFSC "must determine at the initial public hearing whether or not the proposed site is consistent and in compliance with county or regional land use plans or zoning ordinances." If a zoning amendment is necessary to permit the proposed plant to be built, it must be granted prior to the submission of the utility's application to EFSC for state approval of the project. However, the need for a new thermal generating facility is based on meeting regional power requirements and the potential impacts of a major facility are likely to be regional in scale. The lack of uniform and comprehensive regional and state land use plans, evaluation techniques, and environmental reporting procedures makes it difficult for local authorities to adequately assess potential impacts, and develop and administer effective regulatory programs. Most new major power facilities are located in rural areas whose governmental authorities may lack adequate manpower and financial resources to fully assess potential environmental and socioeconomic impacts of a such a project. Although faced with complex and of ten controversial issues, some local authorities may find it hard to refuse tens of millions of dollars of new property tax revenues even to the extent of placing reasonable controls on the project. In other cases local authorities may be equally unable to overcome ill-informed local opposition to new facilities. We conclude that the rational development of new energy resource/technologies will require, on the one hand, improved methods of communicating relevant information to local decision areas, and, on the other hand, effective means of working out acceptable compromises between local and broader interests. 


\section{APPENDIX III: SECOND GENERATION FUSION POWER PLANT}

The ideal second generation fusion power system, as defined in this study, has no major direct social costs other than the production of waste heat. This appendix discusses a solution to the waste heat problem which would have major social benefits. We will assume that the fusion power plant has the following characteristics: urban or suburban siting; low hazard, pollution and despoliation; and high efficiency through utilization of thermal energy. Possible uses of thermal energy are given in Table IIIa. Of these uses of thermal energy, three are especially important--district heating, industrial process steam, and greenhouses.

We have prepared two illustrative energy use forecasts for 2010 A.D. The first is a 1 inear extrapolation of U.S. Federal Energy Administration data for 1974-1990 to 2010. The second forecast, the Total Energy Case, assumes the utilization of thermal energy from large steamelectric power plants. Both of these forecasts show energy end-use consumption to be 114.0 Quads in 2010. Yet the energy input in the Total Energy Case is 22.0 Quads lower than the alternative scenario. The significant point of this is that in order to realize this reduction in total energy input to U.S. society as well as comparable reductions in material requirements and social, economic, and environmental impacts requires a steam-electric power plant with the characteristics of the second generation fusion power plant. This conclusion is based on the assumption that it is unlikely that fossil-fueled plants, burner, or breeder reactors will be sited in urban areas in the future.

If thermal energy is substituted for fuels used in the residential, commercial, and industrial sectors for heating and process steam as shown in Table IIIb, this would result in a use of fuels in 2010 which would be at about the same level as that use projected for 1990 by the Federal Energy Administration assuming business as usual and $\$ 16$ imported oil as shown in Figure IIIa. In addition, the remaining 28.0 Quads of waste heat from power plants could be used to heat greenhouses at equal or lower costs than the use of cooling towers in which case the negative impacts of waste heat or thermal pollution would be eliminated completely.

We can envision a future U.S. society whose energy use in the 2lst century is based on a solar/ fusion power system: solar in the southern regions of the United States and second generation fusion power systems in the northern regions. Given the favorable technological assumptions of this study, the development of a future solar/fusion based power system coupled with a strong energy conservation program over the remainder of the 20th century would seem to be our best hope for a sustainable and environmentally benign energy system. 
TABLE IIIa Possible Uses of Thermal Energy (Waste Heat)

A. LIrban

1. Residential and Commercial
a. space heating
b. water heating
c. air conditioning

2. Transportation

a. urban mass transit propulsion

b. snow melting

B. Energy Center (Urban/Suburban)

1. Industrial Process Steam (Major Users)

a. food and kindred products

b. paper and allied products

c. chemicals and allied products

d. petroleum refining and related industry

e. rubber and miscellaneous plastic products

f. textile mill products industry

2. Wastewater Treatment

3. Food Production

a. greenhouses

b. aquaculture

Source: "Use of Steam-Electric Power Plants to Provide Thermal Energy to Urban Areas," A. J. Miller et al., Oak Ridge National Lab, January 1971. 
TABLE IIIb Comparison of Two 2010 A.D. Forecasts

\begin{tabular}{|c|c|c|}
\hline & $\begin{array}{l}\text { Linear } \\
\text { Extrapolation }\end{array}$ & $\begin{array}{l}\text { Total } \\
\text { Energy Case }\end{array}$ \\
\hline \multicolumn{3}{|l|}{ Consumption of } \\
\hline fuels & $92.6 \mathrm{Q}$ & $70.6 Q 21$ \\
\hline electricity & 21.4 & 21.4 \\
\hline thermal energy & 0 & 22.0 \\
\hline Subtotal & $114.0 Q$ & 114.00 \\
\hline Elec. waste heat & 50.0 & 28.0 \\
\hline Total Input & $164.0 Q$ & $142.0 Q$ \\
\hline
\end{tabular}

1/ Based on linear extrapolation of U.S. FEA data for 1974 and forecasts of 1980 , 1985, and 1990 BAU energy use from 1976 U.S. Energy Outlook.

2) Assuming total substitution of thermal energy for equivalent fuel consumption. 


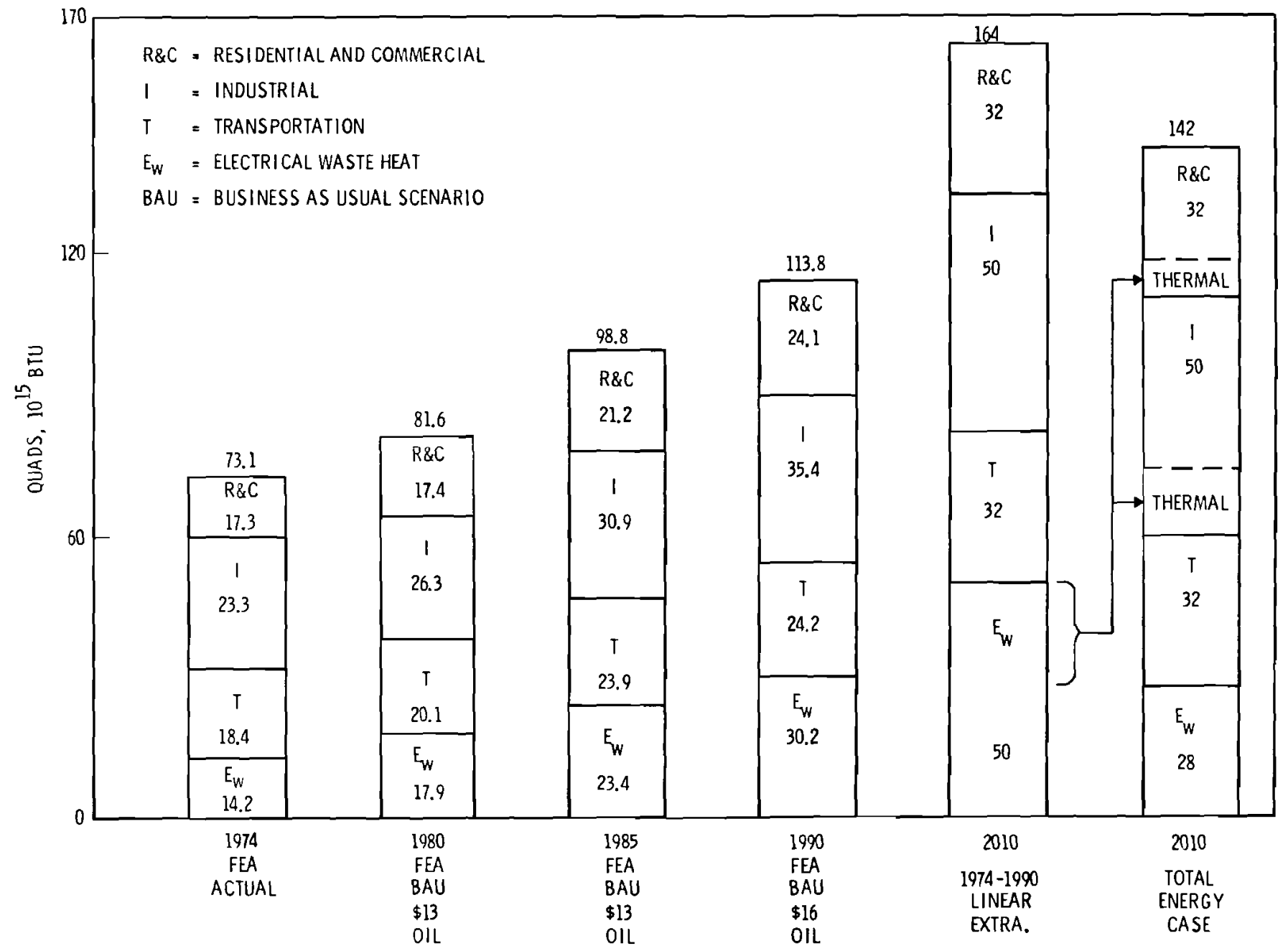

FIGURE IIIa U.S. Energy Use Forecasts 


\section{APPENDIX IV: SELECTED TECHNICAL ENERGY BIBLIOGRAPHY}

\section{ARTICLES/PAPERS}

Abrahamson, D., "Energy Technology: Status and Needs," AMBI0, vol. 2, no. 6, 1973.

Alexander, T., "The Hot New Promise of Thermonuclear Power," Fortune, vol. 81, no. 5, June 1970.

Bupp, I. C., et al., "The Economics of Nuclear Power," Technology Review, vol. 77, no. 4, February 1975.

Coates, J. F., "Technology Assessment: The Benefits. . . the Costs . . the Consequences," The Futurist, December 1971.

Comey, D. D., "Nuclear Power Plant Reliability: The 1973-74 Record," Not Man Apart, vol. 5, no. 8, April 1975.

Commoner, B., "'Energy I, II \& III, ' A Reporter at Large," The New Yorker, February 2, 9, and $16,1976$.

Daly, H. E., "Energy Demand Forecasting: Prediction or Planning?" Journal of the American Institute of Planners, vol. 42, no. 1, January 1976.

Gillette, R., "Recycling Plutonium: The NRC Proposes a Second Look," Science, vol. 188, no. 4190, May 23, 1975.

Gough, W. C., "The Promise of Fusion Power," The Futurist, vol. 7, no. 5, October 1973.

Gross, J. G., et al., "A Systems Analysis Approach to Nuclear Facility Siting," International Institute for Applied Systems Analysis, Austria, RM-74-29, December 1974.

Hafele, W., "Energy Systems," International Institute for Applied Systems Analysis, Austria, RR-73-1, July 1973.

Hirsch, R. L., "Fusion Power: Past, Present and Future," Combustion, vol. 44, no. 12, June 1973.

Jackson, R. M., "Politics and Futurology," Futures, October 1974.

Kenward, M., "Fusion Reactors--The Ultimate Solution?" New Scientist, December 27, 1973. 
Kulcinski, G. L., "Fusion Power--An Assessment of its Potential Impact in the USA," Energy Policy, vol. 2, no. 2, June 1974.

Lessing, L., "Lasers Blast a Shortcut to the U1timate Energy Solution," Fortune, vol. 89, no. 5, May 1974.

Linstone, H. A., "Four American Futures: Reflections on the Role of Planning," Technological Forecasting and Social Change \#4, pp. 41-60, 1972.

Marien, M., "A World Institute Guide to Futures Periodicals," Fields Within Fields, no. 12, Summer 1974.

Marien, M., "Views of Society's Next Stage," Fields Within Fields, no. 13, Fall 1974.

Mills, R. G., "Economic and Environmental Aspects of a First Generation Fusion Power Plant," 1974 IECEC Proceedings, ASME, New York, 1974.

Mitroff, I. I., and M. Turoff, "Technological Forecasting and Assessment: Science and/or Mythology?" Technological Forecasting and Social Change \#5, pp. 113-134, 1973.

Mohr, P. B., "Some Economic Aspects of Power Conversion for Fusion Reactors," 1970 IECEC

Proceedings, American Nuclear Society, Illinois, 1970.

Myers, B., "Thermonuclear Reactors and Electric Power Generation, A Survey," 1970 IECEC Proceedings, American Nuclear Society, Illinois, 1970.

Rose, D. J., "Fusion and 0ther Long-Range Strategies," Consulting Engineer, vol. 40, no. 3, March 1973.

Rose, D. V., "Energy Policy in the U.S.," Scientific American, vol. 230, no. 1, January 1974.

Sagan, L. A., "Human Costs of Nuclear Power," Science, vol. 177, no. 4048, August 11, 1972.

Weinberg, A. M., "Social Institutions and Nuclear Energy," Science, vol. 177, no. 4043, July 7, 1972.

Weismantel, F. E., "Fusion's Engineering Phase," Chemical Engineering, vol. 81, no. 17, August 19, 1974.

Wood, B., et a1., "The Fusion Superstation," The Consulting Engineer, vol. 38, no. 1, January 1974. 
BOOKS/REPORTS

Bauer, R. A., Second-Order Consequences, A Methodological Essay on the Impacts of Technology, MIT Press, Massachusetts, 1969.

Berkshire County Regional Planning Commission, Evaluation of Power Facilities: A Reviewer's Handbook, Massachusetts, Apri1 1974.

Breese, G., et al., The Impact of Large Installations on Nearby Areas, Sage Publications, Beverly Hills, California, 1965.

Cochran, T. B., The Liquid Metal Fast Breeder Reactor, An Environmental and Economic Critique, Johns Hopkins, Resources for the Future, Inc., Washington, D. C., 1974.

Committee on Interior and Insular Affairs, Energy "Demand" Studies, An Analysis and Appraisal, U.S. House of Representatives, Ninety-Second Congress, September 1972.

Cottrell, F., Energy and Society, The Relation Between Energy, Social Change, and Economic Development, McGraw-Hi11, New York, 1955.

Dow Chemical Company, Energy Industrial Center Study, National Science Foundation, June 1975.

"The Energy Crisis: Reality or Myth," The Annals, American Academy of Political and Social Science, November 1973.

The Energy Index 1974, Environment Information Center, New York, 1974.

Fabricant, N., and R. M. Hallman, Toward a Rational Power Policy: Energy, Poljtics and Pollution, George Braziller, New York, 1971.

Federal Energy Regulation Study Team, Federa? Energy Regulation: An Organizational Study, USGPO, Washington, D. C., April 1974, no. 5210-00386.

Hammond, A. L., et al., Energy and the Future, American Association for the Advancement of Science, 1973 .

Hetman, Francois, Society and the Assessment of Technology, Organization for Economic CoOperation and Development, Paris, France, 1973.

Hotte1, H. C., and J. B. Howard, New Energy Technology--Some Facts and Assessments, MIT Press, Massachusetts, 1971 . 
Joint Economic Committee, The Economy, Energy, and the Environment, Congress of the United States, September 1970.

Jones, M. V., A Technology Assessment Methodology, Some Basic Propositions, vol. 1, Mitre Corp., Virginia, 1971.

Lovins, A. B., World Energy Strategies: Facts, Issues and Options, Ballinger Publishing Co., Cambridge, Mass., 1975.

Lovins, A. B., and J. H. Price, Non-Nuclear Futures, The Case for an Ethical Energy Strategy, Ballinger Publishing Co., Cambridge, Massachusetts, 1975.

Miller, A. J., et al., Use of Steam-Electric Power Plants to Provide Thermal Energy to Urban Areas, Oak Ridge National Laboratories, Tennessee, ORNL-HUD-14, January 1971.

Mills, R. G., ed., Fusion Power Plant, Plasma Physics Lab, Princeton University, New Jersey, August 1974.

1976 National Energy Outlook, U.S. Federal Energy Administration, Washington, D.C., 1976.

"The No-Growth Society," Daedalus, Journal of the American Academy of Arts and Sciences, Fal1 1973.

Perspectives on Benefit-Risk Decision Making, The National Academy of Engineering, Washington, D.C., 1972.

Project Independence Blueprint: Final Task Force Reports, USGPO, Washington, D.C., 1974.

Rimberg, D., Utilization of Waste Heat from Power Plants, Noyes Data Corporation, New Jersey, 1974.

Schurr, S. H., ed., Energy, Economic Growth, and the Environment, Johns Hopkins, Resources for the Future, Inc., Washington, D. C., 1972.

Schmalz, A. B., ed., Energy: Today's Choices, Tomorrow's Opportunities, World Future Society, Washington, D. C., 1974 .

Social Costs for Alternative Means of Electrical Power Generation for 1980 and 1990, Argonne National Laboratories, NTIS ANL-8093-V3, March 1973.

Sporn, P., The Social Organization of Electric Power Supply in Modern Societies, MIT Press, Massachusetts, 1971. 
A Time to Choose, America's Energy Future, Energy Policy Project of the Ford Foundation, Ballinger Publishing Co., Cambridge, Massachusetts, 1974.

Transition, Office of Energy Research and Planning, Office of the Governor, State of Oregon, January 1975.

Wakefield, R. A., A Dynamic Study of Total Energy System Long Term Feasibility, dissertation, University of Washington, Seattle, Washington, 1975.

Watt, K. E. F., The Titanic Effect, Planning for the Unthinkable, Sinauer Associates, Inc., Connecticut, 1974 .

Willrich, M., and T. B. Taylor, Nuclear Theft: Risks and Safeguards, Ballinger Publishing Co., Cambridge, Massachusetts, 1974. 
A. A. Churm ERDA Chicago Patent Group

9800 S. Cass Avenue

Argonne, IL 60439

J. W. Beal

ERDA Div. of Magnetic

Fusion Energy

Washington, DC 20545

S. 0. Dean

ERDA Div. of Magnetic Fusion Energy

Washington, DC 20545

E. E. Kintner

ERDA Div. of Magnetic

Fusion Energy

Washington, DC 20545

J. M. Williams

ERDA Div. of Magnetic Fusion Energy

Washington, DC 20545

J. N. Grace

ERDA Div. of Magnetic

Fusion Energy

Washington, DC 20545

J. Baublitz

ERDA Div. of Magnetic

Fusion Energy

Washington, DC 20545

3 F. E. Coffman

ERDA Div. of Magnetic

Fusion Energy

Washington, DC 20545

J. F. Decker

ERDA Div. of Magnetic

Fusion Energy

Washington, DC 20545

3 K. M. Zwilsky

ERDA Div. of Magnetic Fusion Energy

Washington, DC 20545

Dr. Philip M. Stone

ERDA Applied Plasma Physics

Program

Washington, DC 20545

G. W. Kuswa

ERDA Div. of Laser Fusion

Washington, DC 20545
OFFSITE

R. Blaunstein

ERDA Div. of Biomedical

and Environmental Research

Washington, DC 20545

H. M. Busey

ERDA Div. of Military

Application

Washington, DC 20545

M. A. Bell

ERDA Div. of Safety

Standards and Compliance

Washington, DC 20545

27 ERDA Technical Information Center

M. S. Kaminsky

Argonne National Laboratory

9700 S. Cass Avenue

Argonne, IL 60439

V. A. Maroni

Argonne National Laboratory

9700 5. Cass Avenue

Argonne, IL 60439

P. M. Persiani

Argonne National Laboratory

$9700 \mathrm{~S}$. Cass Avenue

Argonne, IL 60439

M. Petrick

Engineering and Technology

Division

Argonne National Laboratory

9700 S. Cass Avenue

Argonne, IL 60439

W. E. Parkins, Manager

Atomics International

Component Engineering and

Technology Division

North American Rockwell

P. 0. Box 309

Canoga Park, CA 91304

D. Gurinsky

Brookhaven National Laboratory ERDA Brookhaven Area Office Upton, NY 11973

H. J. Kouts

Brookhaven National Laboratory ERDA Brookhaven Area Office Upton, NY 11973

S. Pearlstein

Brookhaven National Laboratory

ERDA Brookhaven Area Office

Upton, NY 11973

\section{OFFS ITE}

J. R. Powell

Brookhaven National Laboratory ERDA Brookhaven Area Office Upton, NY 11973

A. J. Impink, Jr.

Carnegie Melion University

Pittsburgh, PA 15213

R. A. Gross

Plasma Research Laboratory

236 SW Mudd Bldg.

Columbia University

New York, NY 10027

W. C. Gough

Electric Power Research Inst.

3412 Hillview Ave.

Palo Alto, CA 94304

G. R. Hopkins

Gulf General Atomic

P.0. Box 1111

San Diego, CA 92112

Zeinab Sabri

Iowa State University

261 Sweeney Hall

Nuclear Engineering Department Ames, IA 50010

R. Borg

Lawrence Livermore Laboratory

P.0. Box 808

Livermore, CA 94550

$T$. K. Fowler

Lawrence Livermore Laboratory P. 0. Box 808

Livermore, CA 94550

R. Moir

Lawrence Livermore Laboratory

P.0. Box 808

Livermore, CA 94550

A. Carl Haussmann

Lawrence Livermore Laboratory

P.0. Box 808

Livermore, CA 94550

J. Hovingh

Lawrence Livermore Laboratory P. 0. Box 808

Livermore, CA 94550

R. F. Post

Lawrence Livermore Laboratory

P.0. Box 808

Livermore, CA 94550

C. J. Taylor

Lawrence Livermore Laboratory

P.0. Box 808

Livermore, CA 94550 
$R$. Werner

Lawrence Livermore

Laboratory

P.0. Box 808

Livermore, CA 94550

L. L. Wood

Lawrence Livermore

Laboratory

P.0. Box 808

Livermore, CA 94550

W. Bauer

Division Supervisor

of Physical Research

Sandia Labs Livermore

Livermore, CA 94550

L. Booth

Los Alamos Scientific Laboratory

CTN Research

P.0. Box 1663

Los Alamos, NM 87544

D. J. Dudziak

Los Alamos Scientific

Laboratory

CTN Research

P.0. Box 1663

Los Alamos, NM 87544

D. B. Henderson

Los Alamos Scientific Laboratory

CTN Research

P.0. Box 1663

Los Alamos, NM 87544

E. L. Kemp

Los Alamos Scientific

Laboratory

CTN Research

P.0. Box 1663

Los Alamos, NM 87544

F. L. Ribe

Los Alamos Scientific

Laboratory

CTN Research

P.0. Box 1663

Los Alamos, NM 87544

L. Stewart

Los Alamos Scientific

Laboratory

CTN Research

P.0. Box 1663

Los Alamos, NM 87544

K. Thomassen

Los Alamos Scientific

Laboratory

CTN Research

P.0. Box 1663

Los Alamos, NM 87544
0. K. Harling

Massachusetts Institute of Technology

Cambridge, MA 02139

Bruno Coppi

Department of Physics

Massachusetts Institute of

Technology

Cambridge, MA 02139

L. Lidsky

Dept. of Nuclear Engineering

Massachusetts Institute of

Technology

Cambridge, MA 02139

Norm Rasmussen

Dept. of Nuclear Engineering

Massachusetts Institute of

Technology

Cambridge, MA 02139

David Rose

Massachusetts Institute of

Technology

Cambridge, MA 02139

R. E. Stickney

Mechanical Engineering

Massachusetts Institute of

Technology

Cambridge, MA 02139

J. J. Reinmann

NASA - Lewis Research Center

2100 Bookpark Rd.

Cleveland, $\mathrm{OH} 44135$

Vincent Arp

National Bureau of Standards

Cryogenics Division

Boulder, Co 80302

J. F. CTarke

Oak Ridge National

Laboratory

P.0. Box Y

Oak Ridge, TN 37830

A. P. Fraas

Oak Ridge National

Laboratory

P.0. Box Y

Oak Ridge, TN 37830

J. Rand McNally, Jr. Oak Ridge National

Laboratory

P.0. Box Y

Oak Ridge, TN 37830

D. Steiner

Oak Ridge National

Laboratory

P.O. Box Y

Oak Ridge, TN 37830
OFFSITE

J. Scott

Oak Ridge National Laboratory

P. 0. Box $X$

Oak Ridge, TN 37830

J. Banford

Physics International

2700 Merced St.

San Leandro, CA 94577

R. A. Huse

Public Service Electric

and Gas Co.

80 Park Place

Newark, NJ 07101

M. Gottlieb

Princeton University, PPPL

P.0. Box 451

Princeton, NJ 08540

R. G. Mills

Princeton University

P.0. Box 451

Princeton, NJ 08540

E. C. Tanner

Princeton University

P. 0. Box 451

Princeton, NJ 08540

H. Perkins

Dept. of Chemistry

Princeton University

Princeton, NJ 06540

R. E. Gold

303 Sayre Hall

Forrestal Campus

P.0. Box 451

Princeton, NJ 06540

M. Kristiansen

Texas Tech. University

Lubbock, TX 79409

A. F. Haught

United Aircraft Research Lab.

United Aircraft Corporation

East Hartford, CT 06108

L. Levine

U.S. Naval Research Laboratory Washington, DC 20390

C. Z. Serpan, Jr.

U.S. Naval Research Laboratory Washington, DC 20390

Francis Chen

University of California

Electronics Research

Laboratory

College of Engineering

Berkeley, CA 94720 
A. J. Lichtenberg University of California Electronics Research Laboratory College of Engineering Berkeley, CA 94720

Dave 0 krent

U.C.L.A.

Los Angeles, CA 90024

C. D. Hendricks University of Illinois Nuclear Engineering Laboratory

Urbana, IL 61801

G. H. Miley University of Illinois Nuclear Engineering Laboratory

Urbana, IL 61801

Terry Kammash University of Michigan Nuclear Engineering Department

Ann Arbor, MI 48105

Dean Abrahamson

University of Minnesota

School of Public Affairs

Social Science

Building/309

Minneapolis, MN 55455

W. G. Davey

University of Texas

Department of Physics

Austin, TX 78712

E. Linn Draper, Jr. University of Texas Department of Physics Austin, TX 78712

W. E. Drummond University of Texas Department of Physics Austin, TX 78712

Abraham Hertzberg University of Washington Aerospace Research

Laboratory

316 Guggenheim

Seattle, WA 98105

A. L. Babb University of Washington Nuclear Engineering Department

Seattle, WA 98105

R. Conn

University of Wisconsin

Nuclear Engineering

Department

Madison, WI 53706

G. L. Kulcinski

University of Wisconsin

Nuclear Engineering

Department

Madison, WI 53706

C. W. Maynard

University of Wisconsin

Nuclear Engineering

Department

Madison, WI 53706

D. Lichtman

Department of Physics

University of Wisconsin

Milwaukee, WE 53201

E. E. Donaldson Washington State University

Deparment of Physics

Pullman, WA 99163

D. D. Mahlum

Division of Biomedical

and Environmental Research

Washington, DC 20545

J. V. Vanston

Engineering Science

Building

University of Texas

Austin, TX 78712

Leslie S. Ramsey

450 North 5 th Street

Indiana, PA 15701 
ERDA Richland 0perations Office

W. A. Burns

Atlantic Richfield Hanford Company

J. D. Kaser

Hanford Engineering

Development Labs

D. G. Doran

H. H. Yoshikawa

Battelle-Northwest

D. T. Aase

G. S. Allison

T. W. Ambrose

D. G. Atteridge

D. A. Baker

J. L. Bates

M. A. Bayne

E. R. Bradley

J. L. Brimhall

R. L. Brodzinski

R. J. Brouns

L. R. Bunnell

L. L. Burger

S. H. Bush

N. E. Carter

T. D. Chikalla

R. G. Clark

T. L. Criswell

S. D. Dahlgren

M. T. Dana

D. E. Deonigi

R. L. Dillon

D. A. Dingee

P. J. Dionne

B. H. Duare

J. W. Finnigan

J. C. Fox

J. J. Fuquay

J. E. Garnier

20 R. D. Gastil

B. F. Gore

J. N. Hartley

A. J. Haverfield

U. P. Jenquin

A. B. Johnson, Jr.

R. H. Jones

T. J. Kabele

W. S. Kelly

H. E. Kissinger

D. A. Kottwitz

N. Laegried

B. R. Leonard, Jr

D. L. Lessor

H. B. Liemohn

R. C. Liikala

M. A. McKinnon

R. F. Maness

R. P. Marshall
Battelle-Northwest - Continued

E. S. Murphy

R. U. Helson

U. F. Newman

R. E. Nightingale

D. E. Olesen

L. T. Pedersen

R. T. Perry

D. R. Pratt

L. A. Rancitelli

J. F. Remark

U. S. Renné

R. E. Rhoads

W. D. Richmond

W. F. Sandusky

L. C. Schmid

N. M. Sherer

E. P. Simonen

R. I. Smith

J. K. Soldat

C. W. Stewart

K. B. Stewart

R. W. Stewart

J. A. Strand

D. L. Styris

A. M. Sutey

V. L. Teofilo

G. L. Tingey

M. T. Thomas

R. C. Thompson

L. H. Toburen

T. J. Trapp

R. Wang

R. E. Westerman

L. D. Williams

$10 \mathrm{~J}$. R. Young

M. G. Zimmerman

1 Technical Publications (BH)

5 Technical Information 